\title{
Realization of Mixed WDM Transmission System
}

\author{
Vjaceslavs Bobrovs and Girts Ivanovs
}

Additional information is available at the end of the chapter

http://dx.doi.org/10.5772/47787

\section{Introduction}

Wavelength division multiplexing (WDM) technology for fiber optic transmission systems has been developed and introduced in order to make use of approximately 60 $\mathrm{THz}$ bandwidth that is offered by silica optical fibers "in $[1,3]$ ". In recent years total information carrying capacity of transmission systems was increased for the account of channels number, channel spacing and per channel bit rates. However in this case must take into the account total amount of optical power coupled into a fiber. Coupled power increase resulting in additional transmission impairments caused by nonlinear optical effects (NOE) and its combination with linear distortion mechanisms "in $[4,6]$ ". Generally it leads to distorted transmission in some channels of fiber optic transmission system (FOTS) or even to complete failure of system's channels. It means that informative signals cannot be detected on the other end of the fiber with a required error probability. This reduces system's total carrying capacity and channel's data throughput. Consequently, another system's total transmission capacity increment solution must be found out.

Currently one of the most intensively studied system's total transmission capacity increment solutions is the increasing of system's channel spectral efficiency "in references [7,11]". Actually it is more efficient utilization of available bandwidth. It means that more informative bits are transmitted using one hertz from available frequency band. It ensures that a smaller number of channels must be used to transmit the same amount of informative bits. Channel's spectral efficiency can be increased in three different ways. The first one, the reduction of used system's channel spacing "in [2]". This means that a larger number of transmission channels can be allocated in available frequency band. The second one, the increase of per channel bit rate maintaining previously used channel spacing values for separation of transmission channels "in [10]". And finally the third one is the combination of pervious two ways. 
Obviously that it is easier to achieve a larger channel's spectral efficiency if for optical signal modulation and coding some of novel modulation formats are used. This novel (or advanced) modulation formats provide narrower optical signals spectrum or multilevel encoding schemes that ensure more bits per one symbol than it is in traditional modulation formats, for example, on - off keying (OOK) with non - return to zero (NRZ) encoding format (NRZ - OOK) "in reference[10]". Maximal spectral efficiency, which can be obtained with traditional OOK modulation formats, is about $0.4 \mathrm{bit} / \mathrm{s} / \mathrm{Hz}$ "in [2]". "It has been reported in ref. $[7,8]$ " that using such novel modulation formats as quadrature amplitude modulation (16 - QAM particularly) and orthogonal frequency - division multiplexing(OFDM) together with polarization division multiplexing (PDM) technique it can be achieved SE larger than $6 \mathrm{bit} / \mathrm{s} / \mathrm{Hz}$ and even reaches $7 \mathrm{bit} / \mathrm{s} / \mathrm{Hz}$.

Study object of this chapter is optimal mixed WDM system configuration that provides lowest in system's channels detected signals BER values. This developed mixed WDM system's model is offered for the future design of backbone optical networks and can be considered under the concept of next generation optical network (NGON). Chosen optical signal modulations formats and per channel bit rates, according to authors' thoughts, are the most appropriate and probable at this moment. It was concluded after careful evaluation of current state of optical telecommunication networks, their possible and the most likely development strategy and trends in the future.

\section{Necessity of mixed WDM transmission system}

With the explosive growth in demand for capacity in national, regional, and metropolitan optical networks, high spectral efficiency wavelength division multiplexing transmission becomes essential. Current WDM optical transport systems are primarily based on $10 \mathrm{Gbit} / \mathrm{s}$ channels that are modulated with on - off - keying on a $50 \mathrm{GHz}$ channel grid. Capacity upgrade of these systems calls for $40 \mathrm{Gbit} / \mathrm{s}$ wavelength channels to be carried in the same system "in [5,9]". To achieve this, several technical challenges need to be resolved.

\subsection{Basic principle of WDM}

Wavelength division multiplexing (WDM) is a technology used to combine or retrieve two or more optical signals of different optical center wavelengths in a fiber. It allows fiber capacity to be expanded in the frequency domain from one channel to more than 100 channels. This is accomplished by first converting standard, non - WDM optical signals to signals with unique WDM wavelengths that correspond to the available channel center wavelengths in the WDM multiplexer and demultiplexer. Typically, this is done by replacing non - WDM transceivers with the proper WDM channel transceivers. WDM channels are defined and labeled by their center wavelength or frequency and channel spacing. The WDM channel wavelength assignment is an industry standard defined in ITU - T documentation. Then the different WDM signal wavelengths are combined into one fiber by the WDM multiplexer. In the fiber, the individual signals propagate with little interaction assuming low signal power. For high powers, interchannel interaction can occur. 
Once the signals reach the fiber link end, the WDM demultiplexer separates the signals by their wavelengths, back to individual fibers that are connected to their respective equipment receivers. Optical receivers have a broad reception spectrum, which includes all of C (1530$1565 \mathrm{~nm}$ ) band. Many receivers can also receive signals with wavelengths down to O (12601360) band "in [11]".

The process of combining and separating the different wavelengths in the fiber is the basis of WDM technology. As a rough analogy, a WDM demultiplexer can be thought of as a prism separating different colors of light from the incident white light ray. Each color of light can represent a unique WDM signal. The white light is the aggregate of all colors of light and represents all the WDM signals propagating in the fiber. It should be noted that WDM wavelength and WDM channel have different meanings. WDM wavelength refers to the center wavelength of an optical signal or a WDM channel. WDM channel refers to an optical signal communications path that is defined by a center wavelength and a spectral pass band. It can be full duplex, half duplex, or simplex. Most telecommunication systems require full duplex communication channels. All full duplex fiber communication channels require two optical signals, one in each direction, to work properly. For a two fiber full duplex WDM system, the two laser signals (one at both ends of the fiber link on different fibers) are assigned the same wavelength, which is referred to as the channel assignment. However, in cases where only one fiber is used for full duplex communications, both lasers will have different wavelength assignments and therefore communication channel uses two WDM channels. Typically, most WDM systems will use two fibers for a WDM link. Therefore, the WDM wavelength assignment is the same for both lasers for that channel and is referred to as the channel assignment.

The heart of any WDM system is the basic WDM (also referred to as passive WDM). The basic WDM only consist of optical filters without any electronics. Therefore, it is completely passive and highly reliable. The filters are designed to pass a selected light spectral range, referred to as a channel, with low loss and reject or reflect all other spectrum. A combination of these filters results in a multichannel WDM multiplexer or demultiplexer. At the transmit end, the multiplexer combines the unique wavelengths from each channel port into one common fiber and at the receive end the demultiplexer coupler separates the combined signals from the common fiber to their respective channel ports. For some systems, the multiplexer and demultiplexer units are the same and are interchangeable (universal units) "in [11]".

In recent years the dramatic increase of demand for transmission capacity is observed and to secure an appropriate quality of service (QoS) level telecommunications services providers must constantly and continuously develop their transmission systems in use "in references $[4,12]^{\prime \prime}$. Currently, as a study object of many scientific works have been chosen and focused directly on the fibre total transmission capacity increases, and this can happen in a three different ways. The first one, the existing $10 \mathrm{Gbit} / \mathrm{s}$ Dense WDM system upgrade, but in fact it is the substitution of existing system with $40 \mathrm{Gbit} / \mathrm{s}$ DWDM system or faster, because the only $10 \mathrm{Gbit} / \mathrm{s}$ system components, which can be used in new $40 \mathrm{Gbit} / \mathrm{s}$ system, are fibre, boosters 
and some external modulated lasers, but all transmitter and receiver electrical parts with bandpass filters must be changed to a new one. The second one, channels compaction by location them closer to each other using smaller channel spacing between them, in that way increasing the number of channel in available transmission frequency spectrum "in $[2,15]$ ". In this case, the total transmission capacity increment is achieved only because of increasing the number of channels, as the individual transmission rate in each channel remains unchanged. And the third way, total transmission capacity increment, using channel compaction with simultaneous increment of individual channel's transmission bit rate.

It is clear, that none of the proposed fibre's transmission capacity increment solution can be realized immediately, but it requires a certain amount of time and work, as any solution should be implemented gradually in several stages to avoid unnecessary problems.

\subsection{Application of optical modulation formats}

Since the introduction of the first optical transmission systems, capacities have steadily increased and the cost per transmitted bit has gradually decreased. The core of the global telecommunication network consists today of wavelength division multiplexed optical transmission systems. WDM is for these systems the technology of choice as it allows for a high spectral efficiency, i.e. the transmitted capacity per unit bandwidth. Commercial WDM systems generally use up to 80 wavelength channels with $50 \mathrm{GHz}$ channel spacing and a bit rate of $10 \mathrm{Gbit} / \mathrm{s}$ or sometimes $40 \mathrm{Gbit} / \mathrm{s}$ per wavelength channel. This translates into a spectral efficiency between 0.2 and $0.8 \mathrm{bit} / \mathrm{s} / \mathrm{Hz}$. However, to cope with the forecasted increase in data traffic it will be necessary to develop next - generation transmission systems with even higher capacities. These transmission systems are expected to have a $40 \mathrm{Gbit} / \mathrm{s}$ or more bit rate per wavelength channel, with a spectral efficiency of between 0.8 and 2.0 $\mathrm{bit} / \mathrm{s} / \mathrm{Hz}$. At the same time, such systems should be robust, i.e. provide a tolerance towards transmission impairments similar to currently deployed systems "in [9]".

Traditionally, optical transmission systems have used amplitude modulation. However, for the next generation of transmission systems this is not a suitable choice. They normally require too large channel spacing, have a high optical - signal - to - noise ratio (OSNR) requirement and generate significant nonlinear impairments. Current state-of-the-art transmission systems therefore often use differential phase shift keying (DPSK). Compared to amplitude modulation, DPSK generates less nonlinear impairments and has a lower OSNR requirement. However, due to the high symbol rate (e.g. 40-Gbaud) the robustness against the most significant linear transmission impairments, i.e. chromatic dispersion and polarization - mode dispersion (PMD) is still small. Tunable optical dispersion compensators can be used to improve the chromatic dispersion tolerance and PMD impairments are generally avoided through fiber selection. But optical compensation and fiber selection are generally not suitable for cost-sensitive applications "in references $[17,18]^{\prime \prime}$. Another potential candidate to reduce the symbol rate is polarization multiplexing (POLMUX). This doubles the number of bits per symbol by transmitting independent information in each of the two orthogonal polarizations of an optical fiber "in [5]". 
Our issue in a mixed system solution is offered as a part of common transmission system development, during the transition from traditional use of NRZ - OOK modulation format to alternative modulation formats, such as NRZ - DPSK and 2 - POLSK. Such hybrid solution can be topical in the case of combination or even in the case of different transmission systems merger, which results in the necessity to make a different modulated optical signal transmission over a single optical bus. As well as, such a need may occur in the future, switching traffic from a variety of WDM systems with the help of reconfigurable optical add - drop multiplexers (ROADM) and transmitting it further over common fibre to its destination or to the next ROADM "in [9]". The shift towards alternative optical signal modulation formats is necessary, because one of the major problem need to be overcome, in order to increase the total transmission capacity of core networks and a single fibre, are the reduction of transmission impairments and signal modulation format capability to resist against such impairments.

In high density WDM (HDWDM) systems with a large fibre span length between two optical amplifiers, signal form distortion causes such effects as linear chromatic dispersion, polarization mode dispersion, fibre non - linear effects or thereof combinations. In WDM system channel spacing reduction limiting factor is interchannel crosstalk, which originate due to optical fibre nonlinearities, such as crossphase modulation (XPM), selfphase modulation (SPM) and four - wave mixing (FWM) "in [13]". In order to reduce the impact of those effects, various optical modulation formats are increasingly being studied and offered, which could serve as an alternative to currently used traditional on - off keying. In this way manipulated signals are significantly distorted at high speed and high spectral density transmission conditions "in [14]".

\section{Measurement technique and accuracy}

This research is based on powerful and accepted mathematical simulation software OptSim. It solves complex differential nonlinear Schrödinger equation (NLSE) using split-step Fourier method (SSFM). This equation describes optical signal propagation over the fiber and can be written as Eq. (1) "in [19]":

$$
\begin{aligned}
\frac{\partial}{\partial z} \cdot A+\frac{\alpha^{l}}{2} \cdot A & +j \cdot \frac{\beta_{2}}{2} \cdot \frac{\partial^{2}}{\partial t^{2}} \cdot A-\frac{\beta_{3}}{6} \frac{\partial^{3}}{\partial t^{3}} \cdot A= \\
& =j \cdot \gamma \cdot|A|^{2} \cdot A
\end{aligned}
$$

where $A(t, z)$ is complex optical field; $z$ is fiber length, $[\mathrm{km}] ; \alpha^{l}$ is linear attenuation coefficient of an optical fiber, $\left[\mathrm{km}^{-1}\right] ; \beta_{2}$ is the second order parameter of chromatic dispersion, $\left[\mathrm{ps}^{2} / \mathrm{nm}\right] ; \beta_{3}$ is the third order parameter of chromatic dispersion, $\left[\mathrm{ps}^{3} / \mathrm{nm}\right] ; \gamma$ is nonlinear coefficient, $\left[\mathrm{W}^{-1} \cdot \mathrm{km}^{-1}\right] ; t$ is time, $[\mathrm{s}]$. NLSE takes into the account linear and nonlinear affects and they influence to optical signal distortions. The principle of split-step method is better illustrated by (1), which can be written as follows "in [19]": 


$$
\frac{\partial}{\partial z} \cdot A(t, z)=(\widehat{D}+\widehat{N}) \cdot A(t, z)
$$

$\widehat{D}$ is linear operator responsible for linear effects such as dispersion and attenuation "in [19]":

$$
\widehat{D}=-\frac{\alpha^{l}}{2}-j \cdot \frac{\beta_{2}}{2} \cdot \frac{\partial^{2}}{\partial t^{2}}+\frac{\beta_{3}}{6} \cdot \frac{\partial^{3}}{\partial t^{3}}
$$

$\widehat{N}$ is nonlinear operator, which takes into account Kerr and other nonlinear effects (NOEs) "in [19]":

$$
\widehat{N}=j \cdot \gamma \cdot|A|^{2} \cdot A
$$

In general split-step method is based on assumption that linear and nonlinear effects affect optical signals independently. This statement can be considered as true if we assume that all fiber length $z$ is being divided into sufficiently small spans $\Delta z$, and only then these linear and nonlinear effects by turns are taken into account for each $\frac{\Delta z}{2}$ segment.

There are two basic algorithms for realization of SSFM: time domain split step (TDSS) and frequency domain split step (FDSS). These two algorithms differ only with an approach that is being used for calculation of linear operator $\widehat{D}$. While in both cases nonlinear operator $\widehat{N}$ is being calculated in time domain "in [19]".

Operator $\widehat{D}$ is being fully characterized by its impulse response $h(t)$ and it is mathematically correct to calculate its influence to $A(t, z)$ optical field using products of mathematical convolution. In TDSS case it can be written as follows "in [19]":

$$
A_{L}[n]=A[n] * h[n]=\sum_{k=-\infty}^{\infty} A[k] \cdot h[n-k]
$$

This algorithm calculates this convolution in time domain and precisely obtains time delay values between signals with different wavelength. In OptSim software this TDSS algorithm is realized using finite impulse reaction (FIR) filters. This sophisticated technique provides complete control of an overall mistake that may occur during all process of calculating. By contrast FDSS calculates $\widehat{D}$ in frequency domain but firstly for this algorithm is necessary to calculate fast Fourier transformation (FFT) from $A[n]$ signal samples and from $h(t)$ impulse reaction. Then it is necessary to use invers FFT (FFT'-1) to convert obtained data array to time sample domain. FDSS algorithm can be mathematically described using following equation "in [19]":

$$
\begin{gathered}
A_{L}^{\prime}[n]=A[n] \otimes h[n]= \\
=F F T^{-1}\{F F T(A[n]) \times F F T(h[n])\}
\end{gathered}
$$

As one can see, then in this case circular convolution is used for obtaining signal sample array $A_{L}^{\prime}[n]$. This array may contain fewer samples than it is necessary to obtain actual convolution products $-A_{L}[n]$ sample array. Hence this algorithm is easier to implement than TDSS and it requires less computation time and resources but serious errors may occur during calculation "in [19]". 
Eq. (2) can be solved assuming that $\widehat{D}$ and $\widehat{N}$ operators are independent and fiber span $\Delta z$ length is small enough (5-100 $\mathrm{m}$ depending on the simulation accuracy requirements). Then optical signal after propagation over $\Delta z$ span can be described in the following manner "in [15]":

$$
A(t, z+\Delta z) \cong \exp \left[\frac{\Delta z}{2} \cdot \widehat{D}\right] \cdot \exp \left\{\Delta z \cdot \widehat{N}\left[A\left(t, z+\frac{\Delta z}{2}\right)\right]\right\} \cdot \exp \left(\frac{\Delta z}{2} \cdot \widehat{D}\right) \cdot A(t, z)
$$

For the evaluation of system performance will be used such parameter as Q-factor and BER value. $Q=7.03$ (16.94 dB) corresponds to the commonly used reference for BER of $10^{-12}$

Q factor uncertainty range (see Fig. 1) and BER confidence interval magnitude depends on the total number of simulated bits $N_{\text {total }}$ "in [15]":

$$
\operatorname{dev}\left[Q^{*}\right] \equiv \sigma_{Q} \cong \frac{Q}{\sqrt{2 \cdot N_{\text {total }}}},
$$

where $\mathrm{Q}$ is $\mathrm{Q}$-factor value that can be calculated using following Eq. (9) "in references [2, 15]":

$$
\mathrm{Q}=\frac{\left|\mu_{1}-\mu_{0}\right|}{\sigma_{1}+\sigma_{0}}
$$

where $\mu 1,0$ and $\sigma_{1,0}$ are the mean and the standard deviation of the received signal, when a logical " 1 " and " 0 " is transmitted, and $\pi \approx 3.14$ "in references $[3,15]$ ".

$$
\mathrm{BER}=\frac{1}{2} \cdot \operatorname{erfc}\left(\frac{Q}{\sqrt{2}}\right)
$$

Using Eq. (8) Q-factor uncertainty range can be expressed as "in [15]":

$$
\text { range }=20 \cdot \log _{10}\left(\frac{1+\sqrt{\frac{2}{N_{\text {total }}}}}{1-\sqrt{\frac{2}{N_{\text {total }}}}}\right)
$$

As one can see from Fig. 1 Q-factor uncertainty range for 1,024 simulated bits that is used in our schemes is equal to $0.77 \mathrm{~dB}$.

Q-factor and BER value $95 \%\left( \pm 2 \sigma_{Q}\right)$ confidence intervals for $16.94 \mathrm{~dB}$ nominal value can be obtained using Eq. (8) and Eq. (10) assuming that we are dealing with Gaussian distribution. For 1024 of simulated bits these intervals are:

$$
\begin{gathered}
Q_{\text {for } 16.94 \mathrm{~dB}} \in[16.55 ; 17.31],[\mathrm{dB}] \\
\log 10\left\{\mathrm{BER}_{\text {for } 10^{-12}}\right\} \in[-12.97 ;-11.04]
\end{gathered}
$$

As an example we will give BER $95 \%$ confidence interval as a function from the number of simulated bits for $10^{-12}$ nominal. This value will be used as reference for transmission channel with $10 \mathrm{Gbit} / \mathrm{s}$ per channel bitrate (see Fig. 1). 
As one can see, when simulating 1,024 bits at BER $=10^{-12}$, the confidence interval magnitude is less than \pm 1 order. It points to the conclusion that OptSim simulation software allows obtaining sufficiently accurate preliminary results and there is no point to increase the total number of simulated bits, because obtained results accuracy does not improve sufficiently.
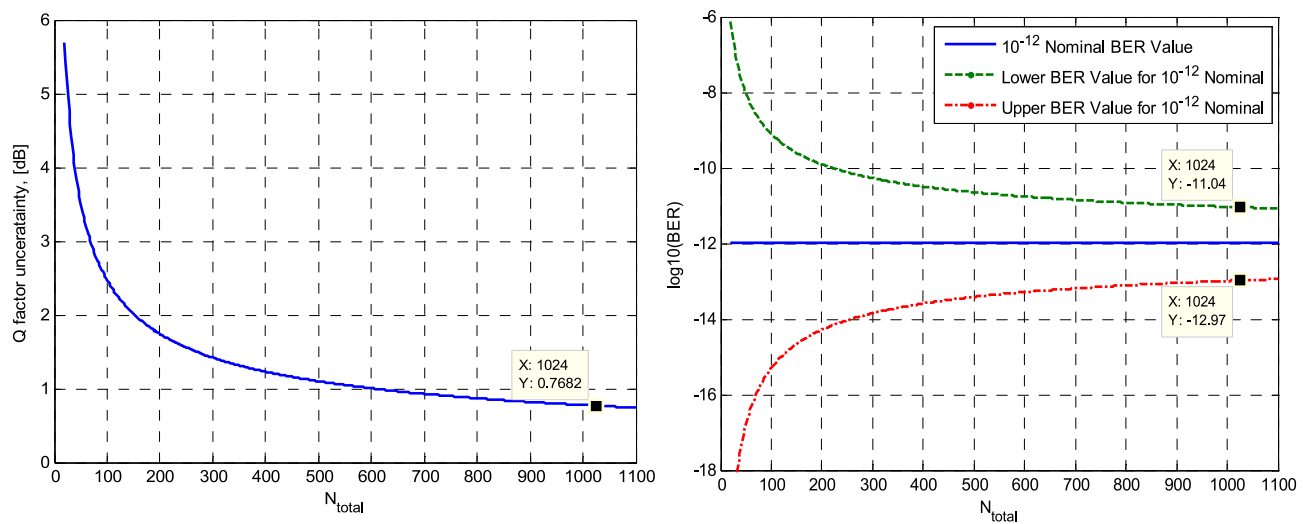

Figure 1. Q-factor uncertainty as a function form total number of simulated bits, and BER value $95 \%$ confidence intervals for $10^{-12}$ nominal.

\section{Mixed WDM transmission system models}

As a start model for our mixed WDM transmission system, $10 \mathrm{Gbit} / \mathrm{s}$ three - channel system was chosen. In this system optical signal modulation formats applied in each system's channel are different. Per channel transmission bit rate is chosen equal to $10 \mathrm{Gbit} / \mathrm{s}$, because our research is focused on ultra - long haul mixed HDWDM transmission system development, which expecting existing $10 \mathrm{Gbit} / \mathrm{s}$ system's infrastructure use and further it's development.

\subsection{Simplest model of mixed WDM}

In the mentioned system's first channel optical signal is transmitted for which modulation differential phase shift keying with non - return - to - zero encoding technique is used (NRZ - DPSK). For the system's second channel on - off keying method and NRZ encoding is used, despite the fact, that NRZ - OOK modulation format is not well situated for high density WDM systems with a large number of transmission channels and high transmission rate and, as consequence of that, a high total transmission capacity. This modulation format can be used as a good foundation and reference point for comparison of different modulation formats, because it's traditionally used modulation format in optical transmission systems, due to its relatively simple realization and historical domination "in [2]". As modulation format for the system's third channel binary polarization shift keying (2 - POLSK) was chosen. It's the newest modulation format and in the same times the most promising "in [16]". 
Then all three differently modulated optical signals are combined and transmitted through $50 \mathrm{~km}$ long standard single mode fibre (SSMF), without using optical amplifiers. On the other fibre end optical signals are filtered with optical Gaussian filters, converted to electrical signals and then electrically filtered using Bessel electrical filters (see Fig. 2).

SSMF length was chosen equal to $50 \mathrm{~km}$, because it's better permissible length between two EDFA in an ultra - long haul transmission system, if fibre attenuation coefficient is $0.2 \mathrm{~dB} / \mathrm{km}$ "in [4]". Large amplifier spacing in such system would result in a prohibitive increase in amplified spontaneous emission (ASE) noise and in order to achieve the greater range and information capacity, the amplifiers must be located close together with gain no greater than about $10 \mathrm{~dB}$ and preferably less "in [17]". Amplifier spacing further increment will lead to increase of ASE noise influence and as a result BER grow for each system channel. As well as, we must take into account system's accumulated dispersion level, because $10 \mathrm{Gbit} / \mathrm{s}$ network, where for optical signal modulation NRZ format is used, operates error free only if residual system dispersion is below 1000 $\mathrm{ps} / \mathrm{nm}$. SSMF has $17 \mathrm{ps} / \mathrm{nm}^{*} \mathrm{~km}$ dispersion and this mean that mentioned above dispersion level threshold won't be exceeded if length of the used fibre is below $58 \mathrm{~km}$. In our case, we start studied optical signal transmission over only one span of ultra long haul transmission system and that's why fibre length was taken from its possible optimal configuration.

In the first previously mentioned system for optical signal modulation in all three channels differential binary phase shift keying (DPSK) was used, in the second - the intensity modulation (IM) and in the third - polarization shift keying were used, while the fourth is a mixed transmission system, where for the first channels optical signal modulation NRZ DPSK was used, for the second channel - NRZ - OOK and third - 2 - POLSK.

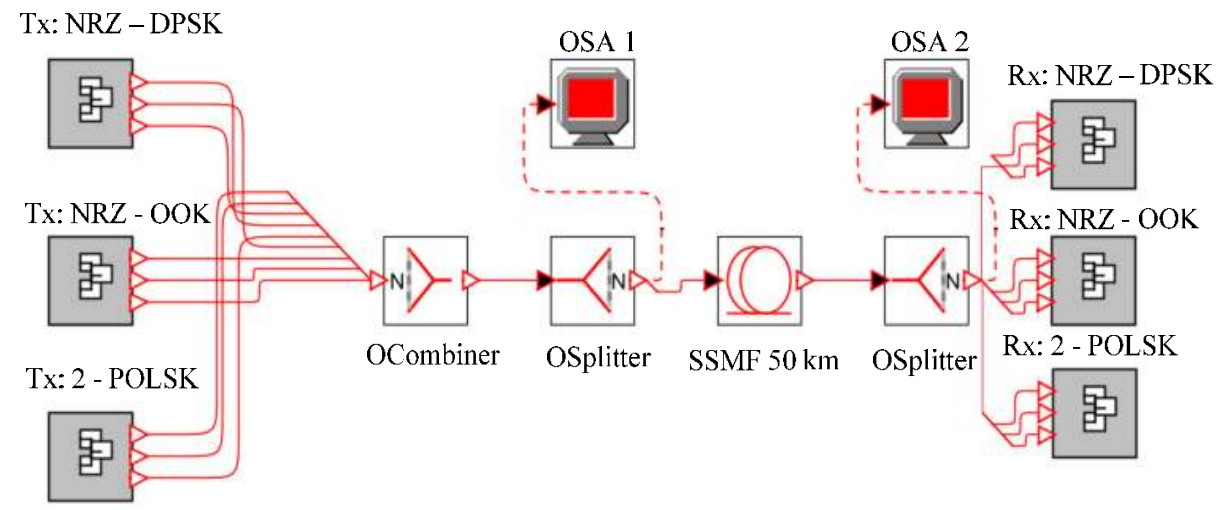

Figure 2. Simulation model of 3 - channel mixed WDM system 


\begin{tabular}{|c|c|c|c|c|c|c|}
\hline \multirow{2}{*}{\multicolumn{2}{|c|}{$10 \mathrm{Gbit} / \mathrm{s}$ WDM System }} & \multicolumn{5}{|c|}{ Channel Spacing, GHz } \\
\hline & & 25 & 37,5 & 50 & 75 & 100 \\
\hline & & \multicolumn{5}{|c|}{ BER } \\
\hline \multirow{3}{*}{ 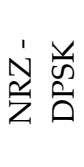 } & $1^{\text {st }}$ & $5,11^{\times} 10^{-12}$ & $6,49^{\times} 10^{-13}$ & $1,78^{\times} 10^{-16}$ & $5,90^{\times} 10^{-17}$ & $6,27^{\times} 10^{-17}$ \\
\hline & $2^{\text {nd }}$ & $3,25^{\times} 10^{-9}$ & $6,12^{\times} 10^{-10}$ & $1,00^{\times} 10^{-15}$ & $1,98^{\times} 10^{-17}$ & $4,00^{\times} 10^{-17}$ \\
\hline & $3^{\text {rd }}$ & $3,18^{\times} 10^{-12}$ & $2,64^{\times} 10^{-13}$ & $3,07^{\times} 10^{-16}$ & $1,23^{\times} 10^{-16}$ & $1,30^{\times} 10^{-16}$ \\
\hline \multirow{3}{*}{  } & $1^{\text {st }}$ & $4,19^{\times} 10^{-29}$ & $9,00^{\times} 10^{-18}$ & $4,56^{\times} 10^{-22}$ & $4,54^{\times} 10^{-26}$ & $3,03^{\times} 10^{-26}$ \\
\hline & $2^{\text {nd }}$ & $1,06^{\times} 10^{-21}$ & $2,53^{\times} 10^{-13}$ & $1,04^{\times} 10^{-21}$ & $4,85^{\times} 10^{-26}$ & $1,84^{\times} 10^{-26}$ \\
\hline & $3^{\text {rd }}$ & $6,79^{\times} 10^{-31}$ & $2,60^{\times} 10^{-16}$ & $1,00^{\times} 10^{-22}$ & $1,62^{\times} 10^{-25}$ & $6,82^{\times} 10^{-26}$ \\
\hline \multirow{3}{*}{ 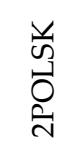 } & $1^{\text {st }}$ & \multirow{3}{*}{$1,00^{\times} 10^{-40}$} & $1,71^{\times} 10^{-29}$ & \multirow{3}{*}{$1,00^{\times} 10^{-40}$} & \multirow{3}{*}{$1,00^{\times} 10^{-40}$} & \multirow{3}{*}{$1,00^{\times} 10^{-40}$} \\
\hline & $2^{\text {nd }}$ & & $4,57^{\times} 10^{-18}$ & & & \\
\hline & $3^{\text {rd }}$ & & $7,12^{\times} 10^{-30}$ & & & \\
\hline \multirow{3}{*}{ 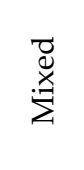 } & $1^{\text {st }}(\mathrm{DPSK})$ & $1,88^{\times} 10^{-25}$ & $9,95^{\times} 10^{-17}$ & $7,70^{\times} 10^{-17}$ & $3,49^{\times} 10^{-17}$ & $2,55^{\times} 10^{-17}$ \\
\hline & $2^{\text {nd }}(\mathrm{NRZ})$ & $3,23^{\times} 10^{-12}$ & $2,63^{\times} 10^{-10}$ & $3,68^{\times} 10^{-24}$ & $3,54^{\times} 10^{-25}$ & $2,18^{\times} 10^{-26}$ \\
\hline & $3^{\text {rd }}(2 \mathrm{POLSK})$ & $1,00^{\times} 10^{-40}$ & $5,12^{\times} 10^{-27}$ & $1,00^{\times} 10^{-40}$ & $1,00^{\times} 10^{-40}$ & $1,00^{\times} 10^{-40}$ \\
\hline
\end{tabular}

Table 1. Simulation results

The configuration type of this system was chosen precisely in order to clarify interchannel crosstalk influence effect to transmission in adjacent channels, if modulation formats applied for each channel are different. Number of channels in systems, where just one modulation format is used for the optical signal modulations, was chosen equal to the number of channels of mixed system under study. It was specially done, in order to provide, that a total amount of input optical power coupled into the fibre would be approximately equal. This condition was specially held, in order to provide, that fibre nonlinearities could become apparent to the same extent and transmission would take place under same conditions, to make a comparison of these four different transmission systems for a range of channel spacing values. Each system simulation was performed for five different channels spacing, whose values were chosen based on the establishment principle of ITU - $T$ Recommendation G.694.1. As the result, systems were simulated at following values of channel intervals: 25, 37.5, 50, 75, $100 \mathrm{GHz}$. Systems channels were grouped around 193.1 $\mathrm{THz}$ central frequency value and were located in C - Band (1530 - $1565 \mathrm{~nm})$. The simulation results are summarized (see Table 1.).

Let's also note, that optical bandpass Gaussian filters with $-3 \mathrm{~dB}$ bandwidth equal to $0.11 \mathrm{~nm}$ were used for signal filtering at $25 \mathrm{GHz}$ channel spacing, rather than in the other cases, where $-3 \mathrm{~dB}$ bandwidth is equal to $0.3 \mathrm{~nm}$. For electrical signal filtering Bessel filters with number of poles equal to 5 and $-3 \mathrm{~dB}$ bandwidth equal to $10 \mathrm{GHz}$ were used. 

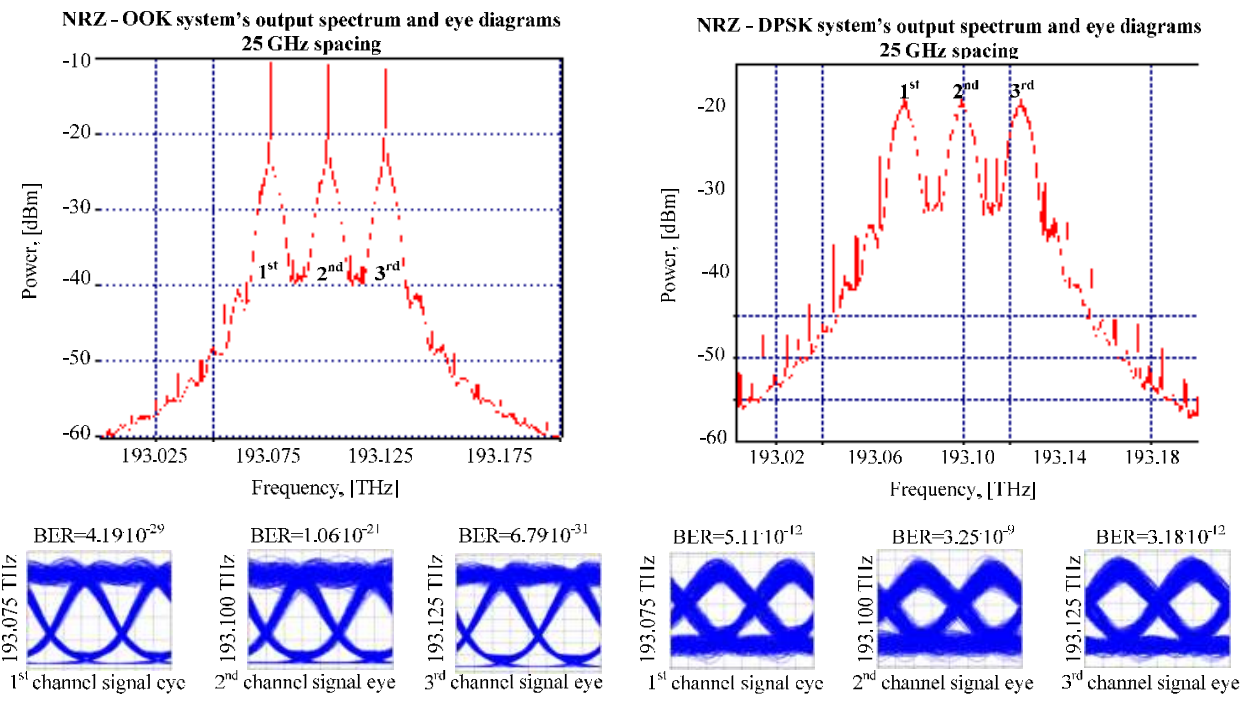

Figure 3. 3 - Channel NRZ - OOK system's output spectrum, signal eye diagrams and BER value in case of $25 \mathrm{GHz}$ channel spacing, and 3 - channel NRZ - DPSK system's output spectrum, signal eye diagrams and BER value in case of $25 \mathrm{GHz}$ channel spacing

At the beginning of the results analysis we will focus on traditionally used NRZ - OOK modulation format. As one can conclude form the simulation results, in the case of small channel spacing values the worst systems bit - error - ratio is for the second system channel. This is explained by the fact, that in this case interchannel crosstalk effects are more quintessential and signal spectrum compaction is maximal affordable (see Fig. 3). As one can see from this figure, further compaction leads to different signal spectrum overlapping and as a consequence imminent grow of BER values. If we increase the value of channel spacing, this difference between BER values of each channel disappears. But if we increase channel spacing up to $37.5 \mathrm{GHz}$, the worst channel BER is already less than desired $10^{-12}$ at the same filter characteristics. In the data transmission networks with 10 Gbit/s bitrates and higher, if forward error correction techniques (FEC) are not used, BER value must be $<10^{-12}$.

If we increase channel spacing value form $37.5 \mathrm{GHz}$ up to $50 \mathrm{GHz}$, the worst channel BER improves till 1.04:10-21. Further increment of spacing form 50 to $75 \mathrm{GHz}$ or even up to 100 $\mathrm{GHz}$ at the given modulation and coding format, as well as bit rate, is not needed, because the BER improvement is not significant (see Fig. $4-5$ ). 


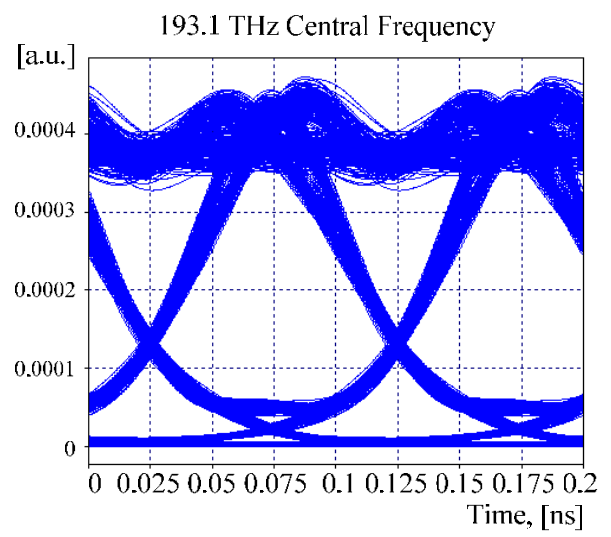

Figure 4. Eye diagram of the worst ( $\left.2^{\text {nd }}\right)$ NRZ - OOK system's channel, $50 \mathrm{GHz}$ channel spacing and $\mathrm{BER}=1.04 \cdot 10^{-21}$

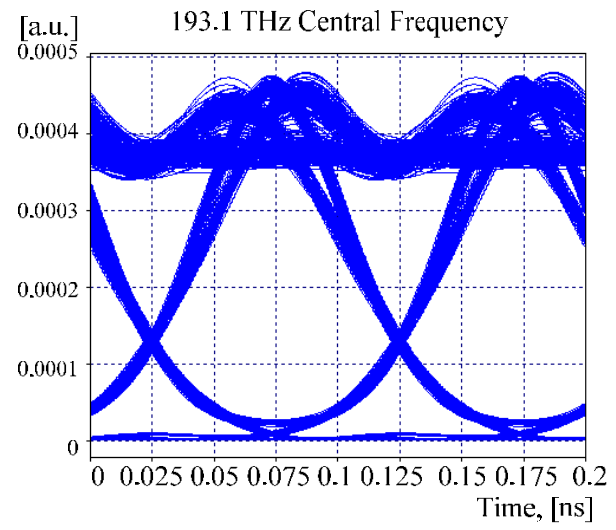

Figure 5. Eye diagram of the best (2nd) NRZ - OOK system's channel, $100 \mathrm{GHz}$ channel spacing and $\mathrm{BER}=1.84 \cdot 10^{-26}$

If we use for optical signal modulation NRZ - DPSK format, the resulting BER values for each simulated channel at certain channel spacing values is several orders worse than it is in the NRZ - OOK format cases (see Fig. 6 - 7). Channel spacing reduction form $100 \mathrm{GHz}$ to 50 $\mathrm{GHz}$, leads to reduction of the worst channel bit - error - rate by one order. This lets make a conclusion about NRZ - DPSK modulation formats suitability to high spectral density transmission conditions. It's non-susceptible to channel spacing decreases or increases, if it happens to specified threshold values, above which a sudden channel degradation process is unavoidable. 


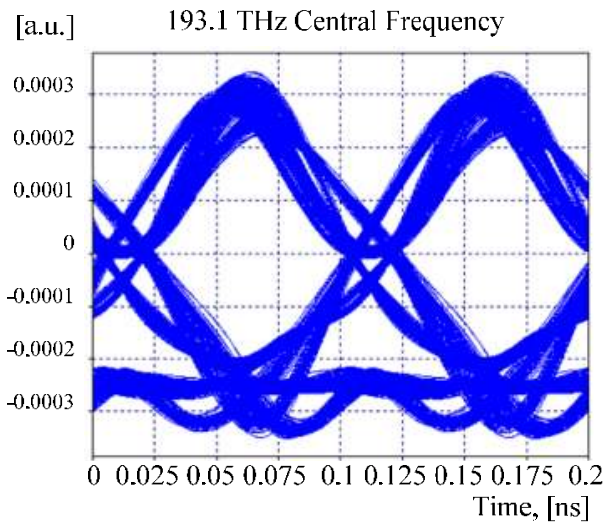

Figure 6. Eye diagram of the best $\left(2^{\text {nd }}\right) \mathrm{NRZ}-\mathrm{DPSK}$ systems channel, $\Delta \mathrm{f}=100 \mathrm{GHz}$ and $\mathrm{BER}=4.00 \cdot 10^{-17}$

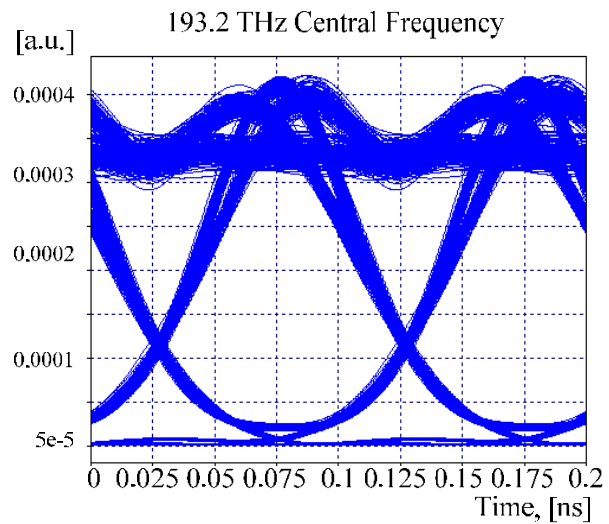

Figure 7. Eye diagram of the worst ( $\left.{ }^{\text {rd }}\right)$ NRZ - OOK systems channel, $\Delta \mathrm{f}=100 \mathrm{GHz}$ and $\mathrm{BER}=6.82 \cdot 10^{-26}$

However, if the channel spacing is reduced to $25 \mathrm{GHz}$, then all three channels BER values are greater than required $10^{-12}$ but middle channels BER is even greater than ITU $-\mathrm{T}$ defined $10^{-9}$. If the modulation format, applied for optical signal in each WDM system transmission channel, is polarization shift keying (2 - POLSK), it is possible to achieve the best possible of channel BER values, irrespective to the channel spacing values as compared to other modulation formats. This is possible due to 2 - POLSK modulated signal spectrum (see Fig. 8). As can been seen, 2 -POLSK modulated optical signal spectrum is narrower than NRZ DPSK and NRZ - OOK modulated signal spectrum. This property provides to a data signals greater error protection, when it is spread through the optical fibre transmission systems, and WDM signal spectrum lines at the beginning and at the end differ only by the level, spectrum extension and nonlinear effect influence are minimal. 
If in multi-channel communication system for optical signal modulations different modulation formats are used, then obtained BER values for each channel will depend not only on the individual modulation format capability to resist from interchannel distortion, but also form that, which modulation format is used in the channel, which is the source of this disorders. This feature gets stronger on small $(<50 \mathrm{GHz})$ channel spacing values, and the obtained simulation results for mixed system allow us to conclude this.

If in a mixed system 50, 75 or $100 \mathrm{GHz}$ channel spacing are used for channel separation, then the channel BER values corresponding to BER values obtained for systems, where only one modulation format is used for the optical signal modulation. It is approximately $10^{-17}$ in NRZ - DPSK case, about $10^{-25}$ in NRZ - OOK and $10^{-40}$ in 2 - POLSK. Reducing channel spacing to $37.5 \mathrm{GHz}$, become evident special features of combined transmission and they stand out even more against the background, if $25 \mathrm{GHz}$ interval is used for channel separation. As it can be seen from the obtained results, the first channel, where is used phase modulation, BER level is several orders lower $\left(10^{-25}\right)$ than it is for the first channel of 3 - channel NRZ DPSK system $\left(10^{-12}\right)$ (see Fig. 8), the same can be applied to the second channel of the mixed system $\left(10^{-12}\right)$ and $2^{\text {nd }}$ channel $\left(10^{-21}\right)$ of 3 - channel NRZ - OOK system (see Fig. 8).
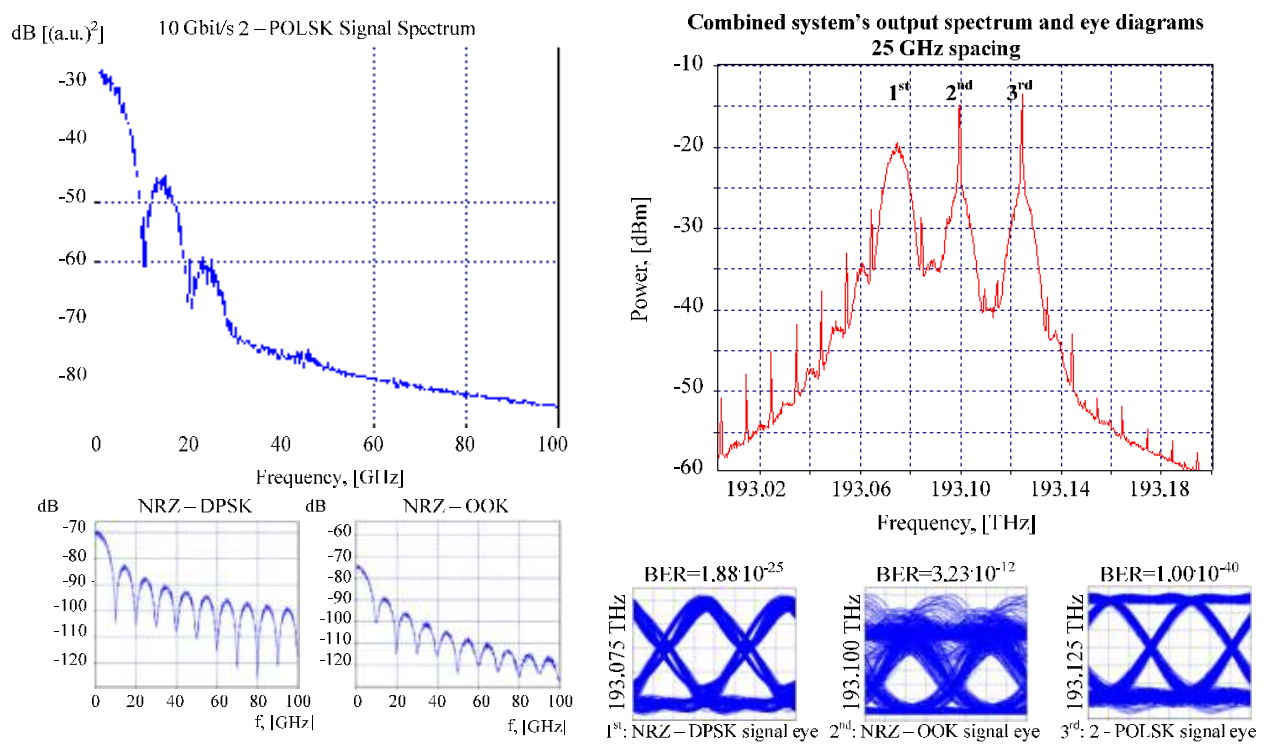

Figure 8. NRZ - DPSK, NRZ - OOK, 2 - POLSK optical signal spectrums at the transmitter end after electrical conversion, and 3 - Channel mixed system's output spectrum, signal eye diagrams and BER value in case of $25 \mathrm{GHz}$ channel spacing

As one can see from these figures, eye opening in both cases are materially different, eye opening for mixed system is narrower than for traditional NRZ - OOK system's $2^{\text {nd }}$ channel signal, if $25 \mathrm{GHz}$ interval is used for channel separation. 
The next step for mixed WDM system performance evaluation is to increase the channel quantity, bitrate and also transmission line length. Upgraded mixed WDM scheme contains nine channels, which are grouped in three groups with an identical transmitter and receiver block configuration but with different channel central wavelengths. It was specially done in order to take into account linear and nonlinear crosstalk influence, which experience central's group channels from adjacent channels. The central group consists from channels number 1 to 3, left group consists from channels number 4 to 6 and right group - from 7 to 9 . For further system's analysis we will use only channels number $1-3$, but $4-6$ and $7-9$ is used as sources of transmission impairments.

In the first channel as in previous model the NRZ - OOK signal optical modulation format is used. This modulation format can be used as a reference point for comparison of different modulation formats. It is traditionally used modulation format in optical transmission systems due to its relatively simple realization and historical domination "in references $[8,12]$ ". Data transmission rate for this channel is chosen equal to $40 \mathrm{Gbit} / \mathrm{s}$. For the system's second channel 2 - POLSK modulation format was chosen, because it's the newest and in the same time the most promising modulation formats for optical transmission systems "in [2]". In this case per channel bit rate was chosen equal to $40 \mathrm{Gbit} / \mathrm{s}$. And finally, as modulation format for the system's third channel NRZ - DPSK was chosen. Per channel bit rate was chosen equal to $10 \mathrm{Gbit} / \mathrm{s}$.

Modulation format allocations to each system's channels was performed on the basis of the fact that such modulation formats distribution among channels provides the lowest possible average BER value for system channels at $10 \mathrm{Gbit} / \mathrm{s}$ per channel bit rate and $25 \mathrm{GHz}$ channel spacing, comparing to other five possible formats distribution variants. As for per channel bit rate assignment, then such variant provides $\mathrm{SE}=0.4 \mathrm{bit} / \mathrm{s} / \mathrm{Hz}$ and an average BER value not greater than $10^{-40}$, if for CD compensation ideal FBG is used (see Fig. 9). Comparing with two other mixed data rates mixed system variants, which can provide $\mathrm{SE}=0.4 \mathrm{bit} / \mathrm{s} / \mathrm{Hz}$, then their can secure BER $<10^{-12}$ or even $<10^{-14}$, but their average channel BER $>10^{-40}$ "in [3]". Thus, as a simulation model of mixed system was chosen a transmission system with a following configuration: [NRZ - OOK (40 Gbit/s, $193.025 \mathrm{THz})$ ] - [2 - POLSK (40 Gbit/s, $193.100 \mathrm{THz})]$ - [NRZ - DPSK (10 Gbit/s, $193.175 \mathrm{THz})]$.

As one can see (see Fig. 9), then SE equal to $0.4 \mathrm{bit} / \mathrm{s} / \mathrm{Hz}$ was obtained in case, if $75 \mathrm{GHz}$ interval is used for channel separation. That channel spacing value was selected based on the establishment principle of ITU - T Recommendation G.694.1, which provides a frequency grid for dense wavelength division multiplexing applications. The frequency grid, anchored to $193.1 \mathrm{THz}$, supports a variety of channel spacing's ranging from $12.5 \mathrm{GHz}$ to $100 \mathrm{GHz}$ and wider. Afterwards all optical signals from nine channels are combined and transmitted through $50 \mathrm{~km}$ SSMF using $4 \mathrm{dBm}$ fixed output power optical amplifier, which operates on basis of EDFA. This amplifier is necessary, because we simulate optical signal transmission through one span of ultra-long haul system.

The output power level is chosen equal to $4 \mathrm{dBm}$ due to the fact that this level can ensure the lowest average BER values for transmission channels of that configuration mixed transmission systems but with bit rate of $10 \mathrm{Gbit} / \mathrm{s}$ per channel and $25 \mathrm{GHz}$ channel spacing 
comparing to other fixed output power levels "in [3]". On the other fiber end optical signals are filtered with optical Super Gaussian filters, converted to electrical signals and then electrically filtered using Bessel electrical filters.


Figure 9. Mixed HDWDM system 1 st/2nd/3rd channel's BER correlation diagram, detected signals eye diagrams and BER values at $75 \mathrm{GHz}$ channel spacing

In order to achieve the greater range and information capacity, the amplifiers must be located close together with gain no greater than $10 \mathrm{~dB}$ and preferably less "in [2]". Amplifier spacing further increment will lead to increase of ASE noise influence and as a result BER growth for each system channel. As well as, we must take into account system's accumulated chromatic dispersion management strategy, which will be the next sections main goal.

\subsection{Chromatic dispersion management strategies}

Chromatic dispersion divides into material and waveguide dispersion.Waveguide dispersion is caused by physical structure of optical fiber core and cladding (refractive index profile), and as a result different wavelengths propagate at different velocities in the core and cladding. Material dispersion is dominant part of chromatic dispersion, and it is caused by change of optical fiber core and cladding refractive index with wavelength "in [4]".

Dispersion compensating fiber (DCF), fiber Bragg grating (FBG) and optical phase conjugator (OPC) can be used for chromatic dispersion compensation.

DCF has large negative dispersion ( $D=-80 \mathrm{ps} /\left(\mathrm{nm}^{*} \mathrm{~km}\right)$, that helps to compensate chromatic dispersion. Such an optical fiber with negative dispersion is achieved by developing a complex refractive index profile. The effective core area $\left(A_{\text {eff }}\right)$ of a DCF is much smaller than 
standard ITU - T G.652 single mode fiber, thereby dispersion compensating fiber experience much higher optical signal distortions caused by nonlinear optical effects (NOE). Typical dispersion compensating fiber has small effective core area Aeff $=12 \mu \mathrm{m}^{2}$ whereas standard single mode optical fiber has $\mathrm{A}_{\text {eff }}=80 \mu \mathrm{m}^{2}$, and DCF has attenuation coefficient up to $\alpha=0.6$ $\mathrm{dB} / \mathrm{km}$, whereas standard single mode optical fiber has $\alpha=0.2 \mathrm{~dB} / \mathrm{km}$. Impact of nonlinear optical effects can be reduced by lowering optical power "in [4]".

Chirped fiber Bragg grating (FBG) is effective technology for chromatic dispersion compensation, because it is more suitable for large transmission capacity WDM systems. It has grating period which is not constant, but changes linearly over the length of the grating with the shorter grating period located at the beginning of the grating. FBG grating period is distance between two adjacent maximum values of the refractive index.

The fiber grating reflects a narrow spectrum of wavelengths, that are centred at reflected wavelength $\left(\lambda_{B}\right)$ and passes all the other wavelengths. Dispersion affected input pulse with width $\tau$ is passing Chirped fiber Bragg grating and at output its width is decreased by $\Delta \tau$ and shape is restored. Chirped fiber Bragg grating has shorter grating periods at beginning, but over the length of the grating these periods linearly increase. Therefore shorter signal wavelengths are reflected sooner and have less propagation delay through the FBG, but longer signal wavelengths travel further into the fiber grating before they are reflected back and have more propagation delay through the FBG. Typically the length of the fiber grating is from 10 to $100 \mathrm{~cm}$ "in [4]".

A significant advantage of using fiber Bragg grating over DCF fiber is its relatively small insertion loss. For comparison, commercial DCF specified to compensate accumulated chromatic dispersion of 100 to $120 \mathrm{~km}$ standard single mode fiber span have about $10 \mathrm{~dB}$ of insertion loss, whereas a FBG based dispersion compensation unit, capable to compensate the same fiber span length, insertion loss is only up to $4 \mathrm{~dB}$. In contrast to DCF fiber Bragg grating can be used at higher optical powers without inducing nonlinear optical effects. These CD compensation methods described above will be practically implemented in our investigated mixed system model.

\subsection{Advanced model of mixed WDM}

There are three different combined chromatic dispersion compensation methods and one combined method described in this work. These simple CD compensation methods are DCF and FBG, but as a combined CD compensation method for practical realization we offer the compound solution of these two methods (DCF - FBG). In this work we are studied chromatic dispersion compensation solutions that can be implemented in transmitter or receiver side, as close as possible to beginning or end of fiber optical link. In these places it is possible to access directly to the optical fiber and place dispersion compensation modules.

The aim of this research is to find the best chromatic dispersion compensation solution that can be used for implementation and adaptation in already working mixed fiber optical transmission systems to improve the performance of these systems (see Fig. 10). As 

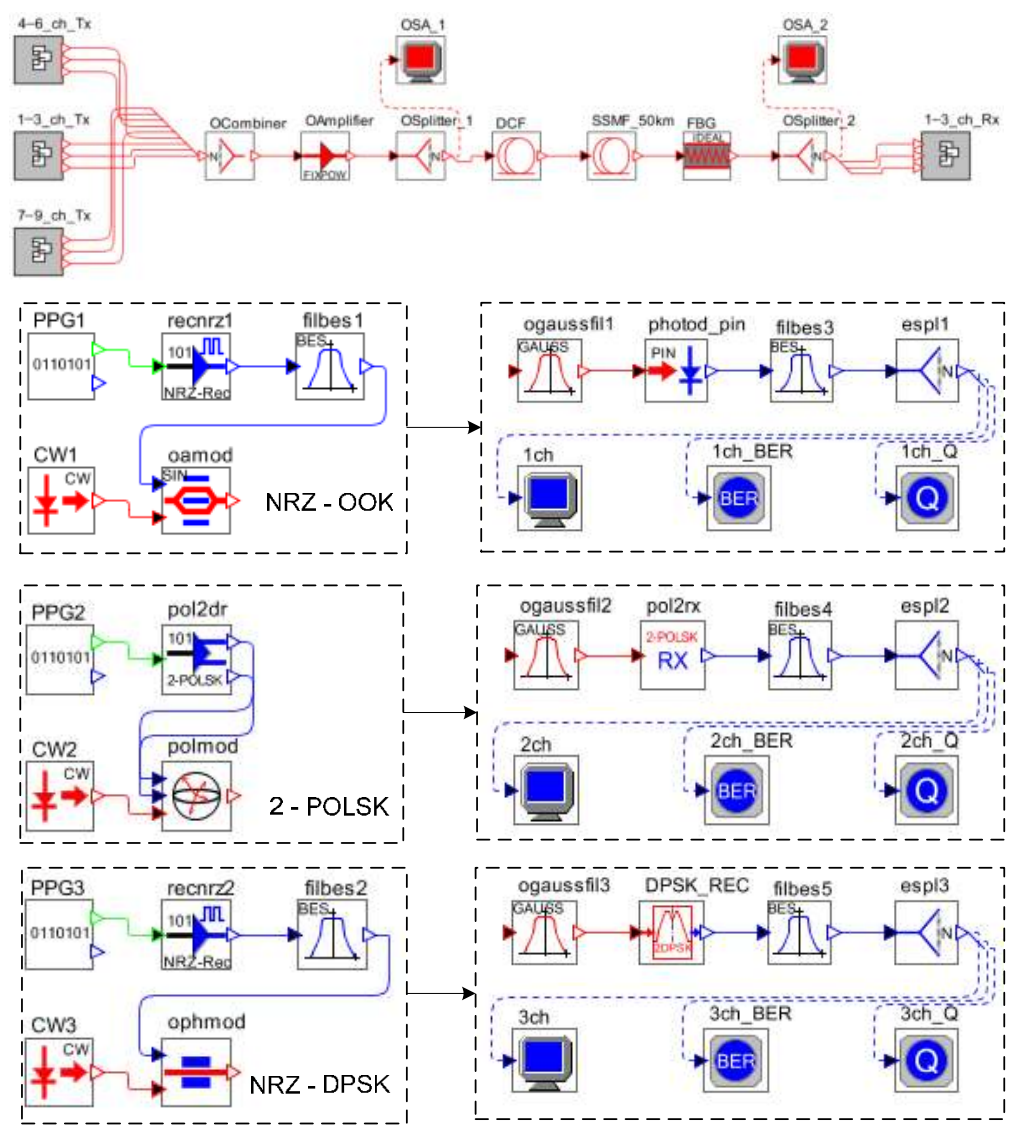

Figure 10. Simulation scheme of 9 - channel mixed HDWDM system and channels' transmitting and receiving parts of NRZ - OOK/ 2 - POLSK/ NRZ - DPSK modulated optical signals

performance improvement we mean the improvement of data transmission rate and / or transmission distance, simultaneously guaranteeing a stable system working condition with the recommended bit error ratio $\mathrm{BER}<10^{-12}$.

If dispersion compensation is not used in developed mixed WDM model, then performance of $1^{\text {st }}$ and $2^{\text {nd }}$ channel is seriously affected by accumulated dispersion. The $3^{\text {rd }}$ channel is affected by accumulated CD at the same level, but this channel's tolerance to CD is much higher, because there is used NRZ - DPSK as a coding format and optical signals are transmitted with $10 \mathrm{Gbit} / \mathrm{s}$ per channel bit rate. Without dispersion compensation the BER value of the $1^{\text {st }}$ and $2^{\text {nd }}$ channel are high (there are many bit errors) and we can assume it is because of inter-symbol interference (ISI), which causes pulse overlapping and receiver has difficulties to separate transmitted bit sequence. In this case BER $>10^{-12}$, system performance is poor and fiber optical WDM transmission system is not able to qualitatively transmit information over distance of $50 \mathrm{~km}$, until CD compensation will not be realized (see Fig. 11). 

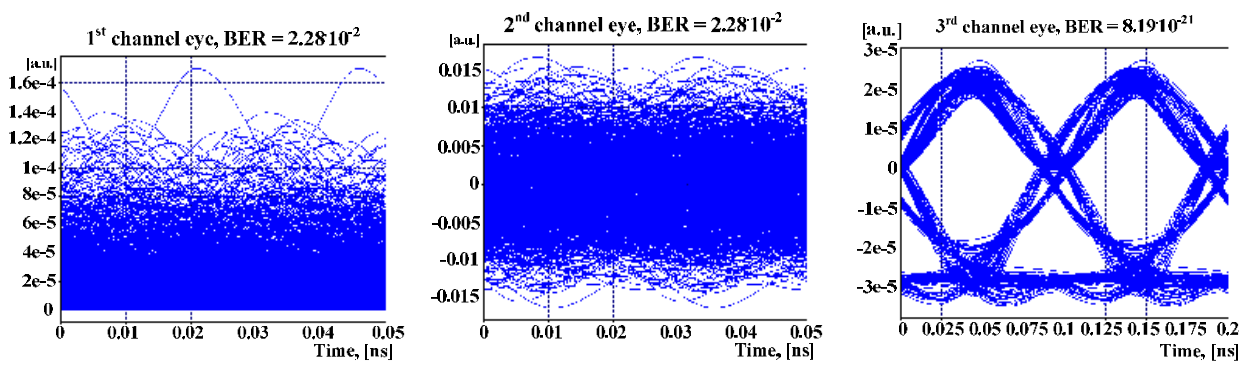

Figure 11. Output eye diagram for all three channels of mixed WDM system without CD compensation

As one can see from obtained detected signal eye diagrams, then $3^{\text {rd }}$ channel's eye is wide open and has almost ideal form. This fact let us to conclude, that in this channel it is possible an error-free transmission even without using some CD compensation schemes. As for $1^{\text {st }}$ and $2^{\text {nd }}$ system's channel, then CD compensation is vital necessary, because eye openings are completely closed for these transmission system channel's eye diagrams. Without CD compensation signal transmission in these channels over $50 \mathrm{~km}$ of SSMF with BER $<10^{-12}$ is impossible.

The first realized compensation method includes the implementation of dispersion compensating fiber (DCF). We used pre- and post-compensation schemes for effective chromatic dispersion compensation in our mixed WDM system. The best proportion of LDCF1 and LDCF2 was studied, where LDCF1 is a DCF fiber length at transmitter side (precompensation) and LDCF2 is DCF fiber length at receiver side (post-compensation), in $\mathrm{km}$. As shown in Fig. 12, we found that the optimal required DCF fiber length proportion is $5 / 5 \mathrm{~km}$.

That proportion of DCF length was found by analyzing $Q$ - value correlation diagrams. As one can see from $2^{\text {nd }}$ channel's (system's worst channel) $Q$ - value correlation diagram, then the highest - value $(20.75 \mathrm{~dB})$ is for fiber length proportion equal to $5 / 5 \mathrm{~km}$. DCF proportion length was chosen on basis of $2^{\text {nd }}$ channel $Q$ - value due to the fact, that this channel is the most affected by transmission impairments and it has BER values higher than for $1^{\text {st }}$ and $3^{\text {rd }}$ channels. Implementation of two DCF fiber spans, with length equal to $5 \mathrm{~km}$ each, provides the best $C D$ compensation results for our investigated mixed fiber optical transmission system.

The second realized compensation method includes the implementation of fiber Bragg grating (FBG). At the first stage we changed FBG compensated CD value from $-1000 \mathrm{ps} / \mathrm{nm}$ to $-600 \mathrm{ps} / \mathrm{nm}$ with $25 \mathrm{ps} / \mathrm{nm}$ step and found that optimal compensation level providing BER $<10^{-12}$ is equal to $-750 \mathrm{ps} / \mathrm{nm}$. As displayed in Fig. 13, the best BER results for the $1^{\text {st }}$ and $2^{\text {nd }}$ channel can be achieved, if we compensate all CD level, which is accumulated during optical signal transmission over the $50 \mathrm{~km}$ of SSMF (800 ps/nm). The optimal compensation level was chosen on the basis of BER results obtained from the $1^{\text {st }}$ channel of mixed WDM system. If we overcompensate accumulated dispersion (if compensated CD level exceeds $875 \mathrm{ps} / \mathrm{nm}$ then BER value grows rapidly and exceeds $10^{-12}$ value for the systems first channel. 

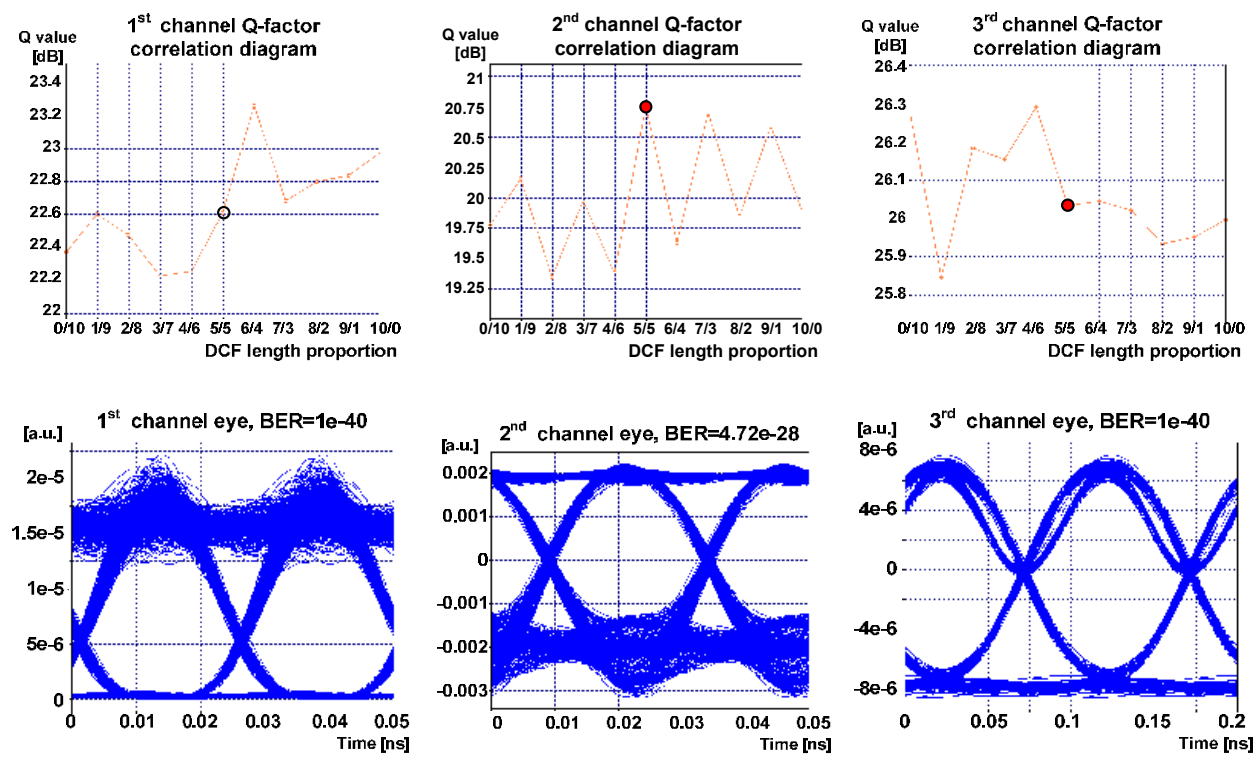

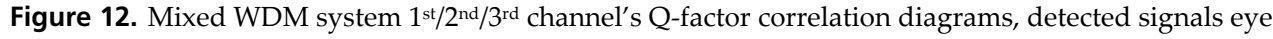
diagrams and BER values at $75 \mathrm{GHz}$ channel spacing

At the second stage the optimal dispersion slope compensation value for FBG used in our simulation scheme was investigated. Dispersion slope value was changed from $-6 \mathrm{ps} / \mathrm{nm}^{2}$ to $-1 \mathrm{ps} / \mathrm{nm}^{2}$ with $0.5 \mathrm{ps} / \mathrm{nm}^{2}$ step. As shown in Fig. 13, the optimal dispersion slope value was chosen equal to $-2.5 \mathrm{ps} / \mathrm{nm}^{2}$. Such a conclusion was obtained basis on the first channel BER value at above mentioned dispersion slope value. This was done due to the fact that BER values for this channel are higher than for the second channel's BER values, but BER values for the third system's channel do not vary depending on compensated CD and dispersion slope levels (see Fig. 13).

In comparison, if we use DCF pre- and post-compensation modules to compensate 750 $\mathrm{ps} / \mathrm{nm}$ of accumulated CD, then the worst system's channel (1 $\left.{ }^{\text {st }}\right)$ BER value is equal to $2.78 \cdot 10^{-14}(\mathrm{Q}=17.60 \mathrm{~dB})$. This value was obtained in case, if used DCF length proportion is 7:3. Numerically this means that pre-compensation module compensates $525 \mathrm{ps} / \mathrm{nm}$, but postcompensation module compensates $225 \mathrm{ps} / \mathrm{nm}$. As one can see, despite the fact that DCF length proportion 5:5 provides better BER results for the $2^{\text {nd }}$ system's channel, it is not providing the optimal $Q$ values (or BER values) in each system's channel. The system's $1^{\text {st }}$ (worst) channel $\mathrm{BER}=2.34 \cdot 10^{-13}(\mathrm{Q}=17.28 \mathrm{~dB})$, if $\mathrm{DCF}$ length proportion, which is used in preand post-compensation modules, is equal to 5:5.

The last inspected dispersion compensation method is combined and includes the common implementation of dispersion compensating fiber (DCF) and fiber Bragg grating (FBG) in our combined fiber optical transmission system. This combined CD compensation method will be named as DCF-FBG. In pre-compensation module DCF fiber will be used, but in 
post-compensation module FBG will be used. For dispersion compensation we changed DCF length LDCF from $0 \mathrm{~km}$ to $15 \mathrm{~km}$, with step $1 \mathrm{~km}$ to find out optimal DCF length and FBG dispersion compensation level proportion, see Fig. 13. The DCF dispersion $D=-80$ $\mathrm{ps} / \mathrm{nm} / \mathrm{km}$ and total accumulated dispersion amount in fiber optical link that must be compensated is $-750 \mathrm{ps} / \mathrm{nm}$ to obtain BER values in each system's channel smaller than $10^{-12}$, as we found out in previous section.
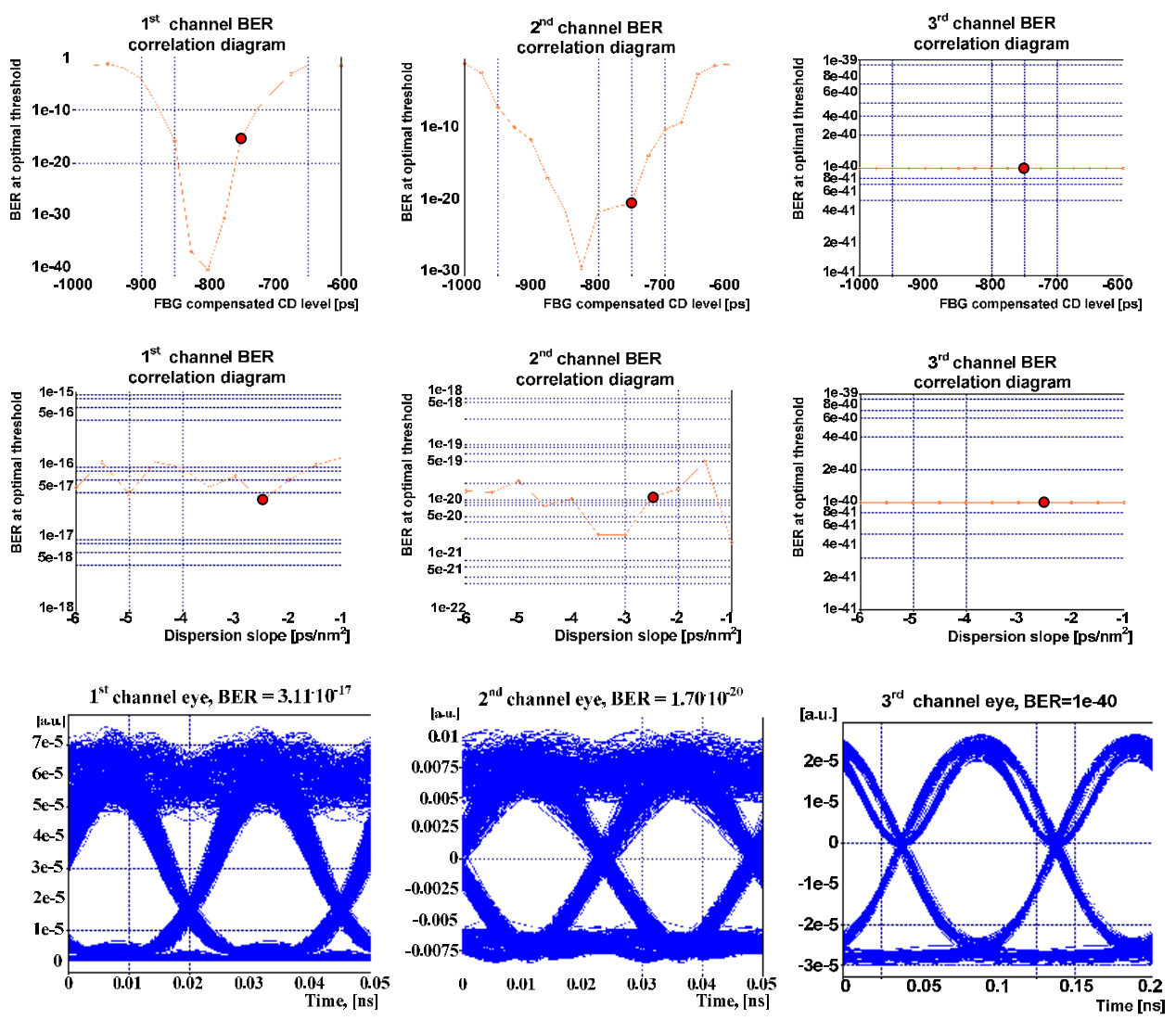

Figure 13. Mixed WDM system $1^{\text {st }} / 2^{\text {nd }} / 3^{\text {rd }}$ channel's BER correlation diagrams, which represents channel's BER value as a function from compensated CD level and BER as a function from compensated dispersion slope value at the dispersion compensation level equal to $750 \mathrm{ps} / \mathrm{nm}$; eye diagrams of detected signals and BER values at chosen compensated $\mathrm{CD}$ and slope values

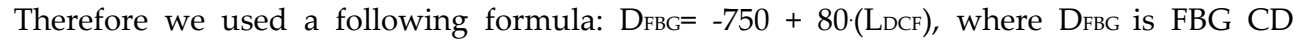
compensation amount provided by FBG. Dispersion amount that can be compensated by DCF fiber can be expressed as DDCF $=-80 \cdot \mathrm{LDCF}$, where LDCF is the length of used DCF.

As one can see, in Fig. 14, the optimal proportion $\left|\mathrm{DDCF}_{\mathrm{DFBG}}\right|$ is $21 / 79 \%$. It means that $21 \%$ of -750 ps/nm must be compensated by DCF, but remaining $79 \%$ must be 
compensated by FBG. Numerically, in our investigated system, it means that DCF compensate $160 \mathrm{ps} / \mathrm{nm}$ ( $2 \mathrm{~km}$ of DCF are used), but FBG compensates remaining 590 ps/nm of accumulated CD amount. This proportion was found basis on the $1^{\text {st }}$ system's channel BER values. This channel is the most affected by chromatic dispersion due to the fact that for optical signal modulation in this channel NRZ - OOK modulation format is used. This modulation format has smaller CD tolerance comparing to 2 - POLSK and NRZ - DPSK formats.
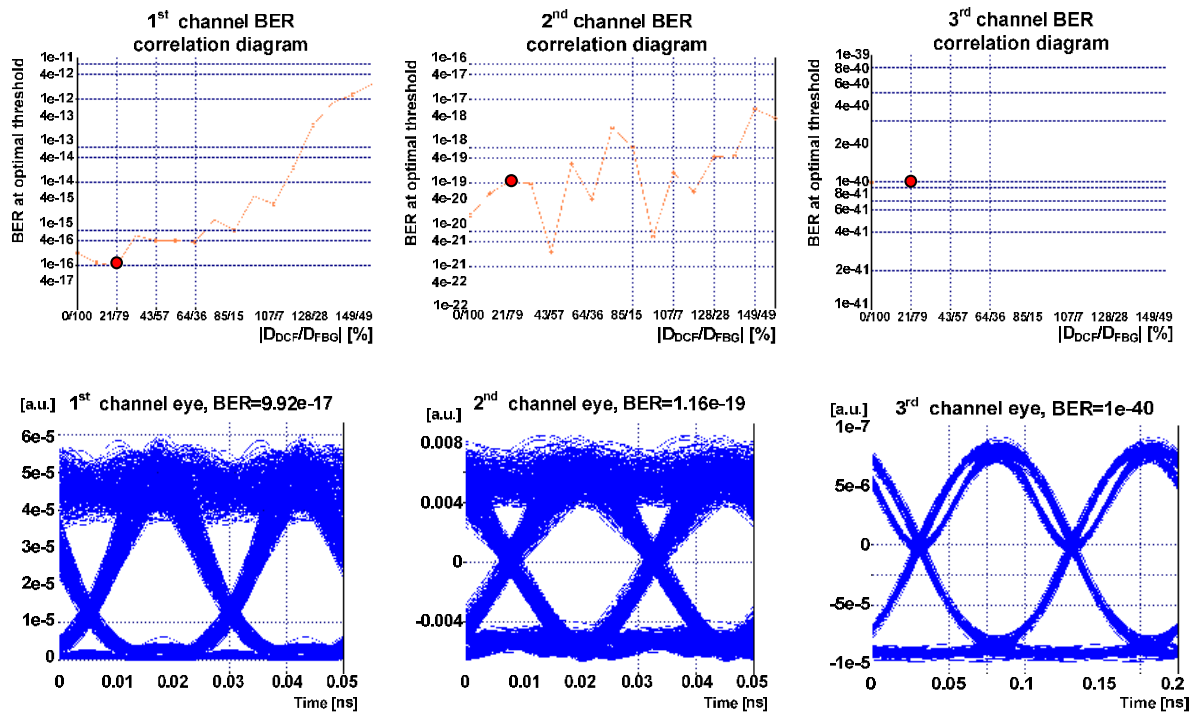

Figure 14. Mixed WDM system 1st/2nd/3rd channel's BER correlation diagrams, eye diagrams of detected signals and BER values at optimal DCF-FBG dispersion compensation proportion level

This is recommended DCF-FBG proportion for optimal accumulated CD compensation in [NRZ - OOK (40 Gbit/s, 193.025 THz)] - [2 - POLSK (40 Gbit/s, $193.100 \mathrm{THz})]$ - [NRZ DPSK (10 Gbit/s, $193.175 \mathrm{THz})]$ mixed fiber optical transmission system.

To identify channel that is a source of larger amount of interchannel crosstalk noise than the rest of system's channels six mixed systems were investigated. These systems differ from each other only with modulation formats distribution among channels. This distribution scheme is as follows: [NRZ-DPSK $(1,2,3,3,2,1)]$-[NRZ - OOK $(2,1,1,2,3,3)]$-[2 - POLSK $(3,3,2,1,2)]$. This configuration represents modulation format and channel's number where one on these formats is used. The system's channels central frequencies are anchored to 193.1 THz according to ITU-T Recommendation G.694.1 and the first channel's central frequency is equal to $193.075 \mathrm{THz}$, the second is $193.100 \mathrm{THz}$ and the third is $193.125 \mathrm{THz}$. After this crosstalk source have been detected simulation model were updated in order to find out the optimal modulation format distribution, which provides the lowest in system's channels detected signals' BER values. For this purpose existing transmission systems model were updated to nine-channel WDM system. These channels are grouped by three 
and these groups have identical transmitter and receiver blocks configuration but with different channels' central wavelengths. It was specially done to take into account linear and nonlinear crosstalk influences to optical signal transmission which are experience central's group channel $\left(1^{\text {st }} 3^{\text {rd }}\right)$ from adjacent groups $\left(4^{\text {th }}-6^{\text {th }}\right.$ and $\left.7^{\text {th }}-9^{\text {th }}\right)$. For system's further analysis we will use only channels number 1-3, but 4-6 and 7-9 are used as sources of interchannel crosstalk.

Then NRZ - DPSK, 2 - POLSK and NRZ - OOK modulated optical signals are combined, optically preamplified with fixed output power erbium-doped fiber amplifier (EDFA) and send over $50 \mathrm{~km}$ of single mode optical fiber. There are two different types of single mode fiber used in this research: standard single mode fiber or SSMF (according to ITU - T Recommendation G.652 D) and non-zero dispersion shifted fiber or NZ - DSF (according to ITU - T Recommendation G.655). Then optical signals are filtered with Super Gaussian optical filters, converted to electrical signals and then electrically filtered using Bessel electrical filters. Fiber span length was chosen equal to $50 \mathrm{~km}$ in order to avoid increase of amplified spontaneous emission (ASE) noise. Larger amplifier spacing would require gain greater than $10 \mathrm{~dB}$, but this in a prohibitive leads to growth of ASE noise "in [14]". The aim of this task was to investigate optimal configuration for mixed WDM systems where differently modulated optical signals are transmitted. To achieve this goal several objectives must be solved.

Firstly it is necessary to identify channel in [1 $1^{\text {st: }}$ NRZ - DPSK, $\left.10 \mathrm{Gbit} / \mathrm{s}, 193.075 \mathrm{THz}\right]-\left[2^{\text {nd: }} 2\right.$ - POLSK, 10 Gbit/s, $193.100 \mathrm{THz}]-\left[3^{\text {rd }}\right.$ : NRZ - OOK, $\left.10 \mathrm{Gbit} / \mathrm{s}, 193.125 \mathrm{THz}\right]$ mixed WDM FOTS that is a source of larger amount of interchannel crosstalk noise than the rest of channels.

For this purpose six different systems were studied. These systems differ from each other only with modulation formats that are used in each particular system's channels. These systems have following configurations:

[NRZ-DPSK]-[NRZ-OOK]-[2-POLSK];
[NRZ-OOK]-[NRZ-DPSK]-[2-POLSK];
[NRZ-OOK]-[2-POLSK]-[NRZ-DPSK];
[2-POLSK]-[NRZ-OOK]-[NRZ-DPSK];
[2-POLSK]-[NRZ-DPSK]-[NRZ-OOK];
[NRZ-DPSK]-[2-POLSK]-[NRZ-OOK].

In each systems channel were determined signals BER values that further were used for system's performance analyze. The obtained results are summarized below (see Table 2). Using these results for each configuration system's average detected signals BER values were calculated. As one can see, sufficiently smaller BER value is for the third mixed system configuration then it is for the rest of possible configuration. The third configuration is as follows: [1 $\left.1^{\text {st: }} \mathrm{NRZ}-\mathrm{OOK} \backslash 193.075 \mathrm{THz}\right]-\left[2^{\text {nd }}: 2\right.$ - POLSK $\left.\backslash 193.100 \mathrm{THz}\right]-\left[3^{\text {rd }}: \mathrm{NRZ}-\right.$ DPSK $\backslash 193.125 \mathrm{THz}$. After careful analysis of these obtained results it was found that investigated mixed system channel, where for optical signals modulation NRZ-DPSK 
modulation format is used, is a source of larger amount of interchannel crosstalk than channels, where NRZ - OOK or 2 - POLSK format is used. This was concluded based on obtained NRZ - OOK and 2 - POLSK channels BER results for different system's configurations. This become evident if we analyze obtained BER values for the fourth, fifth and sixth system.

\begin{tabular}{|l|c|c|c|}
\hline $\mathrm{f}(\mathrm{THz})$ & $1^{\text {st }}$ system & $2^{\text {nd }}$ system & $3^{\text {rd }}$ system \\
\hline 193.075 & $3 \times 10^{-24}$ & $2 \times 10^{-8}$ & $1 \times 10^{-40}$ \\
\hline 193.100 & $9 \times 10^{-12}$ & $9 \times 10^{-25}$ & $1 \times 10^{-18}$ \\
\hline 193.125 & $1 \times 10^{-40}$ & $1 \times 10^{-13}$ & $3 \times 10^{-27}$ \\
\hline Average & $3 \times 10^{-12}$ & $7 \times 10^{-9}$ & $5 \times 10^{-19}$ \\
\hline $\mathrm{f}(\mathrm{THz})$ & $4^{\text {th }}$ systems & $5^{\text {th }}$ system & $6^{\text {th }}$ system \\
\hline 193.075 & $1 \times 10^{-40}$ & $1 \times 10^{-21}$ & $4 \times 10^{-27}$ \\
\hline 193.100 & $2 \times 10^{-8}$ & $6 \times 10^{-25}$ & $8 \times 10^{-14}$ \\
\hline 193.125 & $3 \times 10^{-25}$ & $6 \times 10^{-12}$ & $1 \times 10^{-40}$ \\
\hline Average & $5 \times 10^{-9}$ & $2 \times 10^{-12}$ & $3 \times 10^{-14}$ \\
\hline
\end{tabular}

Table 2. BER values for different mixed systems channels

Firstly let's focus to the fifth system's BER values. As one can see from this configuration scheme then in this case NRZ - DPSK modulated optical signals are transmitted in central system's channel. As a result detected signals BER values in adjacent channels are sufficiently higher than they are in cases, when NRZ - OOK or 2 - POLSK modulated optical signals are located further from NRZ - DPSK channel as it is in the sixth system. Comparing BER results obtained for 2 - POLSK modulated signals in the fourth and sixth system $\left(1 \times 10^{-40}\right.$ and $9 \times 10^{-14}$ respectively), we can conclude that in mixed system detected signals BER value decreases if channel, where these signals are transmitted, is located further from NRZ - DPSK channel.

To assess NRZ-DPSK channel created crosstalk impact to optical signals transmission in all others mixed system's channels previously studied three-channel mixed systems model was modified and supplemented with $2 \times 3$ channels that have appropriate system's configuration. As before, in system channels detected signals BER values were obtained for six different mixed system configurations (see Table 3).

As well as using these data two different channels average BER values were calculated: system's average BER that takes into account all system channels ( $\left.1^{\text {st }} 9^{\text {th }}\right)$; central group channels' average BER that takes into account only channels number one to three. 


\begin{tabular}{|c|c|c|c|c|}
\hline No. & $\mathrm{f}(\mathrm{THz})$ & $1^{\text {st }}$ system & $2^{\text {nd }}$ system & $3^{\text {rd }}$ system \\
\hline 4 & 193.000 & $5 \times 10^{-23}$ & $2 \times 10^{-11}$ & $1 \times 10^{-40}$ \\
\hline 5 & 193.025 & $5 \times 10^{-11}$ & $4 \times 10^{-24}$ & $1 \times 10^{-11}$ \\
\hline 6 & 193.050 & $1 \times 10^{-13}$ & $3 \times 10^{-16}$ & $9 \times 10^{-24}$ \\
\hline 1 & 193.075 & $4 \times 10^{-22}$ & $2 \times 10^{-8}$ & $1 \times 10^{-10}$ \\
\hline 2 & 193.100 & $5 \times 10^{-10}$ & $2 \times 10^{-23}$ & $4 \times 10^{-15}$ \\
\hline 3 & 193.125 & $3 \times 10^{-16}$ & $3 \times 10^{-13}$ & $4 \times 10^{-23}$ \\
\hline 7 & 193.150 & $4 \times 10^{-24}$ & $8 \times 10^{-8}$ & $1 \times 10^{-11}$ \\
\hline 8 & 193.175 & $7 \times 10^{-9}$ & $2 \times 10^{-23}$ & $4 \times 10^{-17}$ \\
\hline 9 & 193.200 & $1 \times 10^{-40}$ & $1 \times 10^{-14}$ & $4 \times 10^{-29}$ \\
\hline \multicolumn{2}{|c|}{ Average $\left(1^{\text {st }}-3^{\text {rd }}\right)$} & $2 \times 10^{-10}$ & $7 \times 10^{-9}$ & $4 \times 10^{-11}$ \\
\hline \multicolumn{2}{|c|}{ Average $\left(1^{\text {st_9 }} 9^{\text {th }}\right)$} & $9 \times 10^{-10}$ & $1 \times 10^{-8}$ & $2 \times 10^{-11}$ \\
\hline No. & $\mathrm{f}(\mathrm{THz})$ & $4^{\text {th }}$ systems & $5^{\text {th }}$ system & $6^{\text {th }}$ system \\
\hline 4 & 193.000 & $1 \times 10^{-40}$ & $3 \times 10^{-31}$ & $9 \times 10^{-27}$ \\
\hline 5 & 193.025 & $3 \times 10^{-11}$ & $2 \times 10^{-23}$ & $6 \times 10^{-15}$ \\
\hline 6 & 193.050 & $3 \times 10^{-24}$ & $2 \times 10^{-11}$ & $3 \times 10^{-11}$ \\
\hline 1 & 193.075 & $1 \times 10^{-11}$ & $2 \times 10^{-15}$ & $4 \times 10^{-23}$ \\
\hline 2 & 193.100 & $1 \times 10^{-8}$ & $3 \times 10^{-26}$ & $1 \times 10^{-14}$ \\
\hline 3 & 193.125 & $4 \times 10^{-22}$ & $3 \times 10^{-10}$ & $5 \times 10^{-10}$ \\
\hline 7 & 193.150 & $1 \times 10^{-12}$ & $2 \times 10^{-15}$ & $3 \times 10^{-22}$ \\
\hline 8 & 193.175 & $3 \times 10^{-8}$ & $5 \times 10^{-24}$ & $2 \times 10^{-13}$ \\
\hline 9 & 193.200 & $1 \times 10^{-23}$ & $3 \times 10^{-12}$ & $1 \times 10^{-40}$ \\
\hline \multicolumn{2}{|c|}{ Average $\left(1^{\text {st }}-3^{\text {rd }}\right)$} & $3 \times 10^{-9}$ & $9 \times 10^{-11}$ & $2 \times 10^{-10}$ \\
\hline \multicolumn{2}{|c|}{ Average $\left(1^{\text {st_-9th }}\right)$} & $4 \times 10^{-9}$ & $3 \times 10^{-11}$ & $5 \times 10^{-11}$ \\
\hline
\end{tabular}

Table 3. BER values for different 9-channel mixed systems' channels

As one can see from obtained data (see Table 3), then the lowest average BER values for $1^{\text {st }}$ till $3^{\text {rd }}$ and $1^{\text {st }}$ till $9^{\text {th }}$ channel are for the third mixed system configuration and they are equal to $\mathrm{BER}_{1 \text { st-3rd }}=4 \times 10^{-11}$ and $\mathrm{BER}_{1 \mathrm{st}-9 \mathrm{th}}=2 \times 10^{-11}$ respectively. But the highest BER values are for the second configuration and they are equal to $B_{E R} 1$ st-3rd $=7 \times 10^{-9}$ and $B_{E R} 1$ st-9th $=1 \times 10^{-8}$. So, BER difference between the best and worst case scenario, corresponding to [(NRZ OOK $) \backslash 193.075 \mathrm{THz}]-[(2-\mathrm{POLSK}) \backslash 193.100 \mathrm{THz}]-[(\mathrm{NRZ}-\mathrm{DPSK}) \backslash 193.125 \mathrm{THz}]$ and [(NRZ - OOK)\193.075 THz]-[(NRZ - DPSK)\193.100 THz]-[(2 - POLSK)\193.125 THz] configuration respectively, is approximately three orders.

In these both cases channel with highest detected signal error probability is the first one, where by the way NRZ-OOK modulated optical signals are transmitted. Comparing BER values obtained for NRZ-OOK and 2-POLSK modulated optical signals for these two systems configuration, we have to conclude that these values differ by no more than two orders $\left(1 \times 10^{-10}\right.$ and $2 \times 10^{-8}$ in NRZ - OOK case and $4 \times 10^{-15}$ and $3 \times 10^{-13}$ for $2-$ POLSK channels). As for NRZ - DPSK channel then the resulting BER values differences in both cases are not significant: $4 \times 10^{-23}$ and $2 \times 10^{-23}$ (see Fig. 15). 

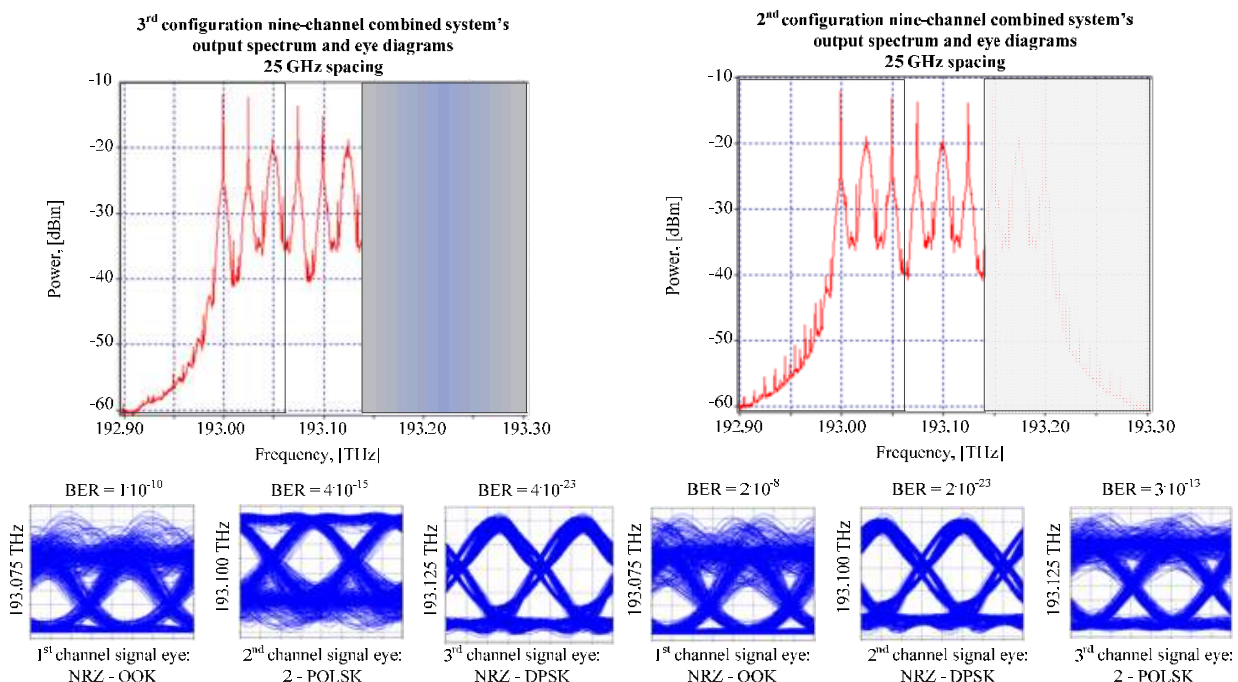

Figure 15. Nine-channel mixed system's with the third configuration output spectrum and eye diagrams in case of $10 \mathrm{Gbit} / \mathrm{s}$ per channel bitrates and $25 \mathrm{GHz}$ channel spacing, and nine-channel mixed system's with the second configuration output spectrum and eye diagrams in case of $10 \mathrm{Gbit} / \mathrm{s}$ per channel bitrates and $25 \mathrm{GHz}$ channel spacing.

As a result, for further research of optimal mixed system configuration will be used as a starting point nine-channel mixed WDM system with the third configuration.

Previously it has been detected that channel, where NRZ - DPSK modulated optical signals are transmitted, is larger amount of interchannel crosstalk source than NRZ - OOK or $2-$ POLSK channels. So, to reduce that type of noise it has been decided to decrease optical power level radiated by distributed feedback lasers (DFB) in continuous wavelength (CW) regime that are used in these channels.

As previously, using these BER results for each system channel average BER value for central channels were calculated. It revealed that in system channels detected signals average BER values are below 10-12 if NRZ - DPSK channels' lasers output power level is in the range from 3.5 to $4.5 \mathrm{dBm}$. The lowest average channels' BER value is reached if these lasers output power is equal to $3.5 \mathrm{dBm}$. In this case BER1st-3rd $=3 \times 10^{-18}$ and the worst channel is the second one ( $2-$ POLSK) and its BER 2 nd $=1 \times 10^{-17}$ (see Fig. 16).

Assuming that we are dealing with one sector of ultra-long haul backbone optical network, it was decided to supplement this model of mixed WDM system with additional optical element is fixed output power optical amplifier. It allowed take into an account ASE noise arising from EDFA which is the most widely used optical amplifier. To find out optimal amplifier output power level, that provides minimal channels' BER values, BER correlation diagram for each were obtained. It represents in systems channels detected signals BER values as a function from amplifier fixed output power level (see Fig. 17). Let is note, that in 
this case NRZ-DPSK channel laser output power level remains unchanged as it was in initial mixed WDM system model "in [2]".

As one can see from Fig. 17, then BER value for the system's first channel varies around 10-11 value, for the second channel around $10^{-16}$ and for the third is $10^{-24}$. Knowing that the worst mixed system's channel is the second one, where 2 - POLSK modulated optical signals are transmitted, and then was decided to choose amplifier output power level that provides minimal BER value exactly in this channel.
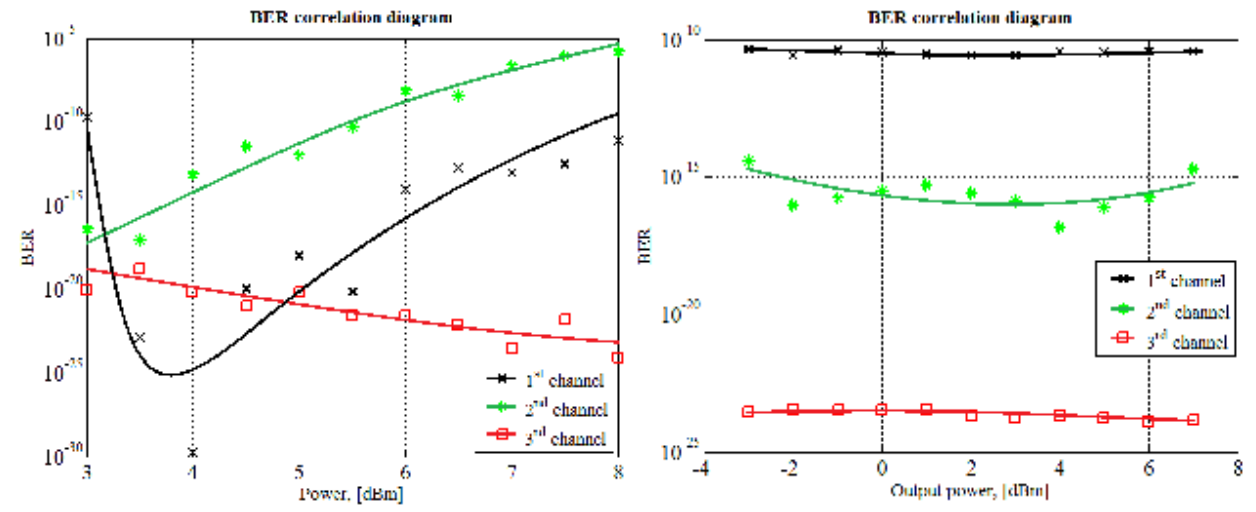

Figure 16. BER as a function from NRZ - DPSK channel laser radiated output power level, and BER as a function form optical amplifier fixed output power level.

Consequently, optical amplifier fixed output power level equal to $4 \mathrm{dBm}$ was chosen. This level provides in the second system's channel detected signals $B_{2 E R}$ nd $=1 \times 10^{-17}$.

If both these optimal parameters are used in mixed system model configuration, then in system channels detected signals BER values are well below the maximal acceptable BER threshold $10^{-12}$, that is defined for $10 \mathrm{Gbit} / \mathrm{s}$ per channel bitrate (see Table 4). Channels BER values for revealed optimal system configuration were obtained for two types of single mode fiber. The first fiber was standard single mode fiber (SSMF) according to ITU-T Recommendation G.652 D and the second was non-zero dispersion shifted fiber (NZ - DSF) according to ITU - T Recommendation G.655.

\begin{tabular}{|l|c|c|c|}
\hline System description & $1^{\text {st }}$ & $2^{\text {nd }}$ & $3^{\text {rd }}$ \\
\hline Initial & $1 \times 10^{-10}$ & $4 \times 10^{-15}$ & $4 \times 10^{-23}$ \\
\hline PNRZ-DPSK $=3.5 \mathrm{dBm}$ & $1 \times 10^{-23}$ & $1 \times 10^{-17}$ & $2 \times 10^{-19}$ \\
\hline FIXPOWER $=4 \mathrm{dBm}$ & $4 \times 10^{-11}$ & $1 \times 10^{-17}$ & $2 \times 10^{-24}$ \\
\hline Optimal and SSMF & $5 \times 10^{-26}$ & $7 \times 10^{-19}$ & $6 \times 10^{-22}$ \\
\hline Optimal and NZ-DSF & $9 \times 10^{-20}$ & $6 \times 10^{-21}$ & $1 \times 10^{-40}$ \\
\hline
\end{tabular}

Table 4. BER value for different system configurations

For these two cases BER results as well as detected signals eye diagrams were compared one to another (see Fig. 17). 
BER value for the first system channel sufficiently dropped from $1 \times 10^{-10}$ to $5 \times 10^{-26}$ if SSMF is used and to $9 \times 10^{-20}$ if NZ-DSF is used. Exactly for this first channel, where NRZ - OOK modulated optical signals are transmitted, experiencing the most radical BER value improvement comparing to 2 - POLSK and NRZ - DPSK channels. In these channels detected signal BER values do not improve so noticeably. The second channel's BER value decreases from $4 \times 10^{-15}$ to $7 \times 10^{-19}$ for SSMF and to $6 \times 10^{-21}$ for NZ - DSF, but the third channel's BER value variation is not essential from $4 \times 10^{-23}$ to $6 \times 10^{-22}$ if SSMF is used. But if in this system instead of SSMF NZ - DSF is used then it is possible to obtain lower BER values for NRZ - DPSK channels. In this channel detected signals BER value decreases to $1 \times$ $10^{-40}$. In addition, coherence between detected signals BER values and channels' central frequency position in C-band (191.6-195.9 THz) was investigated. As well as, for each system channel the worst and the best position in C-band, that provides the highest and the lowest possible signals BER values, respectively, for previously found optimal mixed system's configuration, was revealed (see Table 4). As previously, this research was held for two types of optical fiber: SSMF (G.652 D) and NZ - DSF (G.655).
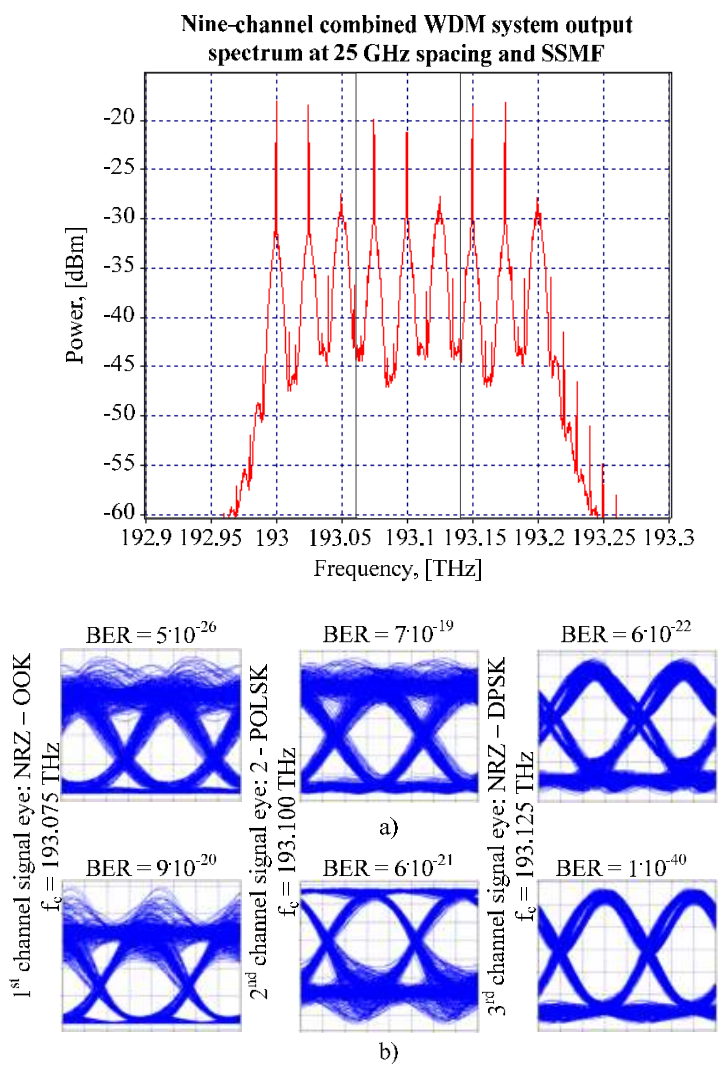

Figure 17. Optimal configuration nine-channel mixed WDM system output optical spectrum and eye diagrams: (a) SSMF; (b) NZ - DSF. 
It showed that depending on channel central frequency the first channel's BER value varies around nominal value of $10^{-20}$ if SSMF is used and around $10^{-30}$ if NZ - DSF. But BER values obtained for the second channel and NZ - DSF are for several orders worse comparing to transmission over SSMF. They vary around $10^{-20}$ and $10^{-25}$, respectively.

In addition, as one can see from Table 5, then BER value obtained for NZ-DSF and the worst case of $2^{\text {nd }}$ channel central frequency is approximately for six orders larger comparing to the worst case of SSMF.

These let us conclude that 2-POLSK modulated signals are not suitable for transmission over NZ - DSF fiber in [NRZ - OOK]-[2 - POLSK]-[NRZ - DPSK] mixed WDM systems and they are sufficiently distorted at appropriate channel central frequency.

\begin{tabular}{|c|c|c|c|c|}
\hline No. & Fiber & $\mathrm{B} / \mathrm{W}$ & $\mathrm{f}_{\mathrm{c}}(\mathrm{THz})$ & BER \\
\hline \multirow{2}{*}{$1^{\text {st }}$} & \multirow{6}{*}{ 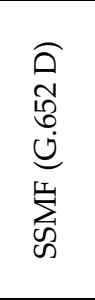 } & best & 195.725 & $8 \times 10^{-26}$ \\
\hline & & worst & 192.350 & $2 \times 10^{-16}$ \\
\hline \multirow{2}{*}{$2^{\text {nd }}$} & & best & 193.950 & $3 \times 10^{-31}$ \\
\hline & & worst & 192.150 & $2 \times 10^{-20}$ \\
\hline \multirow{2}{*}{$3^{\text {rd }}$} & & best & 195.100 & $8 \times 10^{-25}$ \\
\hline & & worst & 192.400 & $7 \times 10^{-19}$ \\
\hline \multirow{2}{*}{$1^{\text {st }}$} & \multirow{6}{*}{ 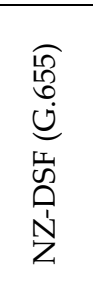 } & best & 193.475 & $1 \times 10^{-39}$ \\
\hline & & worst & 193.925 & $5 \times 10^{-26}$ \\
\hline \multirow{2}{*}{$2^{\text {nd }}$} & & best & 191.925 & $2 \times 10^{-23}$ \\
\hline & & worst & 195.750 & $3 \times 10^{-14}$ \\
\hline \multirow{2}{*}{$3^{\text {rd }}$} & & best & \multirow{2}{*}{ C-band } & \multirow{2}{*}{$1 \times 10^{-40}$} \\
\hline & & worst & & \\
\hline
\end{tabular}

Table 5. Best and worst channels positions in C-band and their BER values

As result system's average BER value is significantly higher than it might be in case of SSMF (see Table 6). In same time the lowest $1^{\text {st }} 3^{\text {rd }}$ channels average BER value is gained with NZ - DSF and it is about two orders lower than in case of SSMF. As for the third channel, then in case of SSMF and different channel central frequencies obtained BER values vary somewhere around $10^{-23}$. Whereas in case of NZ - DSF these values remain constant and approximately equal to $10^{-40}$ in all C-band. It allows to judge about NRZ DPSK modulated optical signals transmission suitability over NZ - DSF single mode optical fiber.

Let is note, that Corning LEAF non-zero dispersion shifted fiber characteristics and parameters were used in OptSim in order to obtain mathematical model of a NZ-DSF. This fiber is the world's most widely deployed NZ-DSF and is specially optimized for high-speed and high capacity long-haul and metro networks. 


\begin{tabular}{|c|c|c|c|}
\hline Characteristics & BER & $\begin{array}{c}2^{\text {nd }} \text { channel } \\
\mathrm{f}_{\mathrm{c}}(\mathrm{THz})\end{array}$ & $1^{\text {st }-3^{\text {rd }} \text { channel }}$ \\
\hline \multirow{3}{*}{ MIN average BER/ SSMF } & \multirow{3}{*}{$3 \times 10^{-23}$} & \multirow{3}{*}{195.750} & $8 \times 10^{-26}$ \\
\hline & & & $2 \times 10^{-24}$ \\
\hline & & & $8 \times 10^{-23}$ \\
\hline \multirow{3}{*}{ MAx average BER/SSMF } & \multirow{3}{*}{$6 \times 10^{-17}$} & \multirow{3}{*}{192.375} & $2 \times 10^{-16}$ \\
\hline & & & $7 \times 10^{-28}$ \\
\hline & & & $7 \times 10^{-19}$ \\
\hline \multirow{3}{*}{ MIN average BER/ NZ-DSF } & \multirow{3}{*}{$5 \times 10^{-25}$} & \multirow{3}{*}{192.825} & $1 \times 10^{-31}$ \\
\hline & & & $1 \times 10^{-24}$ \\
\hline & & & $1 \times 10^{-40}$ \\
\hline \multirow{3}{*}{ MAx average BER/ NZ-DSF } & \multirow{3}{*}{$1 \times 10^{-14}$} & \multirow{3}{*}{195.750} & $1 \times 10^{-27}$ \\
\hline & & & $3 \times 10^{-14}$ \\
\hline & & & $1 \times 10^{-40}$ \\
\hline
\end{tabular}

Table 6. Minimal and maximal in system's $1^{\text {st }}-3^{\text {rd }}$ channel detected signals BER values

\section{Results and discussions}

In summary it can be concluded, that the mixed WDM solution allows combining channels with a variety of modulation formats, which are used for optical signal modulation, in one single transmission system, preserving a previously used channel spacing values. We would like to point out one more time, that such mixed solution of transmission system is being offered as the transition state form traditionally used NRZ - OOK modulation format to the alternative modulation formats, such as NRZ - DPSK or 2 - POLSK, which use provides a number of superior properties due to their abilities of providing greater protection from interchannel crosstalk, less exposed to expression of non-linear effects and better exposed to channel filtration, as well as less exposed to chromatic dispersion effect. By gradually introducing new system channels, can be increased the total transmission capacity of fibre, thus avoiding of core networks bottleneck effect and in the same time minimize growth of non-linear optical effect influences, because the alternative modulation formats are able to provide the same BER levels as traditionally used NRZ - OOK, but only at lower input power levels.

The suitability of different chromatic dispersion compensation methods for the most efficient high - speed mixed HDWDM systems, with a $50 \mathrm{~km}$ of SSMF span length and following system's configuration: [ $1^{\text {st }}$ channel: NRZ - OOK, $\left.40 \mathrm{Gbit} / \mathrm{s}, 193.025 \mathrm{THz}\right]-\left[2^{\text {nd }}\right.$ channel: 2 - POLSK, 40 Gbit/s, $193.100 \mathrm{THz}$ - [3 ${ }^{\text {rd }}$ channel: NRZ - DPSK, 10 Gbit/s, 193.175 $\mathrm{THz}$, has been evaluated. This configuration represents channel's number, modulation format, per-channel data rate and channels' central frequencies at $75 \mathrm{GHz}$ channel spacing. The following recommendations and conclusions are summarized below for the next generation of WDM transmission systems.

- $\quad$ The use of both CD pre- and post-compensation modules together, which might contain DCF of different length, allow to achieve better system's BER values comparing with pre- 
compensation or post-compensation schemes used separately. We have found, that the best $\mathrm{CD}$ compensation and lowest channels BER results for investigated mixed HDWDM systemwith mixed data rates, mentioned above, can be achieved using $5 \mathrm{~km}$ of DCF in pre- and post-compensation modules. The similar results can be achieved using $7 \mathrm{~km}$ of DCF in pre-compensation module and $3 \mathrm{~km}$ in post-compensation module.

- Minimal CD level that needs to be compensated, using FBG, to achieve investigated mixed HDWDM system channels' BER $<10^{-12}$, is equal to $750 \mathrm{ps} / \mathrm{nm}$, without dispersion slope compensation. If CD slope compensation of $-2.5 \mathrm{ps} / \mathrm{nm}^{2}$ is realized in addition to dispersion level compensation of $750 \mathrm{ps} / \mathrm{nm}$, then the worst channel's (NRZ - OOK channel) Q-value increases by $0.17 \mathrm{~dB}$, from $18.25 \mathrm{~dB}$ to $18.42 \mathrm{~dB}$.

- As combined CD compensation methods we have investigated DCF - FBG solution. DCF is used in pre-compensation module, but FBG is used in post-compensation module. The minimal average system's channel BER value can be achieved, if dispersion amount compensated by DCF and FBG is equal to $21 \%$ and $79 \%$ from minimal accumulated CD level, which must be compensated to obtain BER $<10^{-12}$ in each system's channel. In our case this accumulated CD level is equal to $750 \mathrm{ps} / \mathrm{nm}$. Similar results could be obtained, if $57 / 43 \%$ dispersion level compensation proportion is used for realized mixed HDWDM system.

Investigating coherence between BER values and channels' central frequencies position in Cband, it have been stated several facts. Firstly, obtained channels central frequency values for each system channel the worst and the best position in C-band, that provide the highest and the lowest possible detected signals BER values. Secondly, 2 - POLSK modulated signals are not suitable for transmission over NZ - DSF fiber in investigated mixed WDM system, because these signals are sufficiently distorted at appropriate channel central frequency. If mixed system's channels are allocated around nominal of $195.750 \mathrm{THz}$, then obtained average detected signals BER value is about $10^{-14}$ and it is the worst possible case. Whereas the lowest possible average BER value $\left(5 \times 10^{-25}\right)$ can be reached anchored mixed systems channels frequency grid to $192.825 \mathrm{THz}$. Thirdly, NRZ - DPSK modulated optical signals are well suitable for transmission over NZ - DSF.

\section{Author details}

Vjaceslavs Bobrovs and Girts Ivanovs

Riga Technical University, Institute of Telecommunications, Latvia

\section{References}

[1] Cisco Systems (2010) Cisco Visual Networking Index - Forecast and Methodology 20092014, White paper, no.1, pp. 1-17.

[2] Udalcovs, A., Bobrovs, V. and Ivanovs, G. (2011) Investigation of Allowed Channel Spacing for Differently Modulated Optical Signals in Combined HDWDM systems, Electronics and Electrical Engineering 6 (112): 19-24. 
[3] Dutta, A.K., Dutta, N.K. and Fujiwara, M. (2004) “WDM Technologies: Optical Networks" - USA, Elsevier Inc. 336 p.

[4] Bobrovs, V., Spolitis, S., Udalcovs, A. and Ivanovs, G. (2011) Investigation of Chromatic Dispersion Compensation Methods for Combined HDWDM Systems, Latvian Journal of Physics and Technical Sciences, no. 5: 13-27

[5] Miyamoto, Y. (2011) Ultra-High Capacity Transmission for Optical Transport Network, OFC/NFOEC Conference proceedings pp. 1-28.

[6] Sano, A., Masuda, H., Kobayashi, T., Fujiwara, M., Horikoshi, K., Yoshida, E., Miyamoto, Y., Matsui, M., Mizoguchi, M., Yamazaki, H., Sakamaki, Y. and Ishii, H. (2011) Ultra-High Capacity WDM Transmission Using Spectrally-Efficient PDM 16QAM Modulation and C- and Extended L-Band Wideband Optical Amplification, Journal of Lightwave Technology, vol. 29, no. 4: 578-586.

[7] Takahashi, H., Al Amin, A., Jansen, S. L., Morita, I., and Tanaka, H. (2010) Highly Spectrally Efficient DWDM Transmission at 7.0 b/s/Hz Using 8x65.1-Gb/s Coherent PDM-OFDM, Journal of Lightwave Technology, vol. 28: 406-414.

[8] Kikuchi, K. (2008) Coherent transmission systems, in: 34th European Conference on Optical Communication, pp. 1-39.

[9] Bottacchi, S., Beling, A., Matiss A., Nielsen, M. L., Steffan, A.G. and Unterborsch, G. (2010) Advanced Photo receivers for High-Speed Optical Fiber Transmission Systems, IEEE Journal of Selected Topics in Quantum Electronics, 16 (5): 1099-1112.

[10] Udalcovs A., Bobrovs V. and Ivanovs G. (2011) Investigation of Differently Modulated Optical Signals Transmission in HDWDM Systems, Journal of Computer Technology and Application, vol. 2, no. 10: 801-812.

[11] Peucheret, C. (2004) Fibre and component induced limitations in high capacity optical networks. Doctoral thesis, pp. 1-8.

[12] Hamano, H., Ishikawa, G. \& Yamashita, K. (1999) High - speed transmission systems. Fujitsu Sci. Tech. J., 35 (1): 91-99.

[13] Keiser G. (2007) Optical Communications Essentials. McGraw-Hill, 372 p.

[14] Clarke, A. (2007) Optical pulse processing towards Tb/s high - speed photonic systems. Doctoral thesis, pp. 1-14.

[15] Bobrovs, V. \& Ivanovs, G. (2008) Investigation of Mixed Data Rate and Format Transmission in WDM Networks, Electronics and Electrical Engineering. 4(84): 63-66.

[16] Xu, C., Liu, X. \& Wei, X. (2004) Differential Phase-Shift Keying for High Spectral Efficiency Optical Transmissions. IEEE Journal of Selected Topics in Quantum Electronics, 10(2): 281-293.

[17] Bobrovs, V. \& Ivanovs, G. (2009) Investigation of Minimal Channel Spacing in HDWDM Systems, Electronics and Electrical Engineering. 4(92): 53-56.

[18] Chomycz, B. (2009) Planning Fiber Optic Networks. McGraw-Hill, 401 p.

[19] Bobrovs, V., Ivanovs, G. \& Spolitis S. (2011) Realization of Combined Chromatic Dispersion Compensation Methods in High Speed WDM Optical Transmission Systems, Electronics and Electrical Engineering. 5(111): 33-38. 